\title{
Impact of infralimbic inputs on intercalated amygdala neurons: A biophysical modeling study
}

\author{
Guoshi Li, ${ }^{1}$ Taiju Amano, ${ }^{2}$ Denis Pare, ${ }^{2}$ and Satish S. Nair ${ }^{3,4}$ \\ ${ }^{7}$ Department of Psychology, Cornell University, Ithaca, New York 14850, USA; ${ }^{2}$ Center for Molecular and Behavioral Neuroscience, \\ Rutgers State University, Newark, New Jersey 08901, USA; ${ }^{3}$ Electrical \& Computer Engineering, University of Missouri-Columbia, \\ Columbia, Missouri 65211, USA
}

\begin{abstract}
Intercalated (ITC) amygdala neurons regulate fear expression by controlling impulse traffic between the input (basolateral amygdala; BLA) and output (central nucleus; Ce) stations of the amygdala for conditioned fear responses. Previously, stimulation of the infralimbic (IL) cortex was found to reduce fear expression and the responsiveness of Ce neurons to BLA inputs. These effects were hypothesized to result from the activation of ITC cells projecting to Ce. However, ITC cells inhibit each other, leading to the question of how IL inputs could overcome the inter-ITC inhibition to regulate the responses of Ce neurons to aversive conditioned stimuli (CSs). To investigate this, we first developed a compartmental model of a single ITC cell that could reproduce their bistable electroresponsive properties, as observed experimentally. Next, we generated an ITC network that implemented the experimentally observed short-term synaptic plasticity of inhibitory inter-ITC connections. Model experiments showed that strongly adaptive CS-related BLA inputs elicited persistent responses in ITC cells despite the presence of inhibitory interconnections. The sustained CS-evoked activity of ITC cells resulted from an unusual slowly deinactivating $\mathrm{K}^{+}$current. Finally, over a wide range of stimulation strengths, brief IL activation caused a marked increase in the firing rate of ITC neurons, leading to a persistent decrease in Ce output, despite inter-ITC inhibition. Simulations revealed that this effect depended on the bistable properties and synaptic heterogeneity of ITC neurons. These results support the notion that IL inputs are in a strategic position to control extinction of conditioned fear via the activation of ITC neurons.
\end{abstract}

[Supplemental material is available for this article.]

Intercalated (ITC) amygdala neurons occur as multiple densely packed cell clusters distributed along the lateral and medial aspects of the basolateral amygdaloid (BLA) complex. Medial ITC clusters are thought to constitute critical regulators of classically conditioned fear responses (Pare et al. 2004) because they are in a strategic position to control impulse traffic between the sensory input and fear output stations of the amygdala: the BLA and central nucleus (Ce), respectively. Indeed, ITC cells receive glutamatergic afferents from the BLA, and send GABAergic projections to Ce (Pare and Smith 1993a,b; Royer et al. 1999; Jungling et al. 2008). In addition, ITC neurons located dorsally (ITC ${ }_{\mathrm{D}}$ ) at the BLA-Ce border inhibit more ventral ones $\left(\mathrm{ITC}_{\mathrm{V}}\right.$ ) (Royer et al. 2000a), thereby allowing for a spatiotemporally differentiated gating of impulse traffic between BLA and Ce (Fig. 1A; Royer et al. 1999).

Much evidence indicates that medial ITC cell clusters participate in the extinction of conditioned fear responses (Royer and Pare 2002; Jungling et al. 2008; Likhtik et al. 2008). It is currently believed (Pare et al. 2004; Quirk and Mueller 2008) that extinguished conditioned stimuli (CS) activate infralimbic (IL) neurons with glutamatergic projections to ITC cells. In turn, ITC cells would reduce conditioned fear responses by generating feedforward inhibition in fear output Ce neurons (Pare et al. 2004). Consistent with this, IL stimulation dramatically reduces the responsiveness of Ce neurons to BLA inputs (Quirk et al. 2003).

\footnotetext{
${ }^{4}$ Corresponding author.
}

E-mail nairs@missouri.edu; fax (573) 882-0397.

Article is online at http://www.learnmem.org/cgi/doi/10.1101/lm.1938011.
However, IL axons target all medially located ITC cells clusters (McDonald et al. 1996). Since there are inhibitory connections between (Royer et al. 2000a) as well as within ITC cells clusters (Geracitano et al. 2007), it is not immediately clear how IL inputs could overcome the inter-ITC inhibition.

Unfortunately, it is currently difficult to address this question experimentally, because we lack criteria to identify ITC cells on the basis of their extracellularly recorded activity. Thus, we developed a biophysical conductance-based model of the ITC network (Fig. 1B) to study how inter-ITC inhibitory connections affect their responses to IL inputs. A second objective of our study was to examine how the peculiar electroresponsive properties of ITC cells shape their responsiveness to BLA/IL inputs. Indeed, ITC cells express an unusual voltage-dependent $\mathrm{K}^{+}$conductance whose slow-deinactivation kinetics allow them to produce prolonged depolarizing plateaus after a transient suprathreshold depolarization (Royer et al. 2000b). The ability of ITC neurons to transform transient excitatory inputs into a prolonged state of increased excitability may have important consequences for how they regulate conditioned fear. In keeping with this idea, during prolonged auditory CSs, BLA principal neurons show rapidly adapting responses (Quirk et al. 1995, 1997; Repa et al. 2001; Herry et al. 2008). Moreover, pairing CSs with brief (300 msec) electrical IL stimuli reduces conditioned freezing in a temporally specific manner (Milad and Quirk 2002; Milad et al. 2004). At present, it is not clear how such transient responses are converted into sustained behavioral output. We therefore tested the hypothesis that the bistable electroresponsive properties of ITC cells allow them to transform transient BLA/IL signals into a more sustained output. 


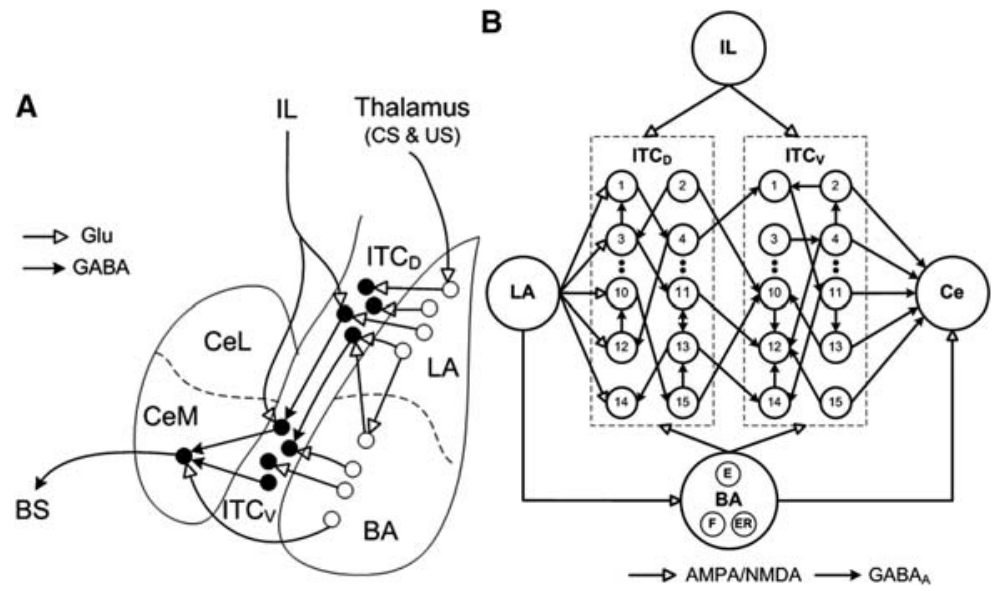

Figure 1. (A) Scheme showing connectivity of the amygdala (adapted from Pare et al. 2004 and reprinted with permission from The American Physiological Society (C) 2004). LA receives thalamic inputs conveying information about the conditioned stimulus (CS) and unconditioned stimulus (US). LA projects to the basal nucleus (BA), and ITC neurons located dorsally (ITC $C_{D}$, which in turn project to ITC cells located more ventrally (ITC $C_{V}$ ). ITC cells contribute GABAergic projections to CeM (central medial nucleus). The BA sends excitatory inputs to both ITC $C_{D}$ and ITC $V$ cells, and to CeM. IL also projects to both ITC $C_{D}$ and ITC $C_{V}$ cells. CeM projects to brainstem structures mediating fear responses. (BS) Brainstem; (Glu) glutamate. (B) Structure of the model ITC network with 15 neurons each in ITC $C_{D}$ and ITC clusters. Each ITC neuron inhibits three randomly selected neurons in the same cluster (only one projection per neuron is shown in the figure). Each ITC $C_{D}$ neuron also inhibits three randomly selected ITCV neurons (e.g., ITC $\mathrm{D}_{\mathrm{D} 2}$ inhibits $\mathrm{ITC} \mathrm{V}_{\mathrm{V} 10}$ ). For clarity and illustration purpose, the figure only shows partial connectivity, which may not be the actual connectivity used in the model (see Supplementary Table S3). The network has five Ce output neurons that receive excitatory inputs from $B A$, and inhibitory inputs from ITC $C_{V}$ neurons. ITC $C_{D}$ and ITC $C_{V}$ : Neurons $1-5$ are of type $A$ neurons (with facilitating output synapses); neurons 6-10 are of type B (with depressing output synapses); and neurons 11-15 are of type $C$ neurons (with constant synapses). See the Materials and Methods section entitled "Presynaptic release probability" for description of facilitating and depressing ITC synapses.

\section{Results}

\section{Overview of the model}

We developed a biophysical conductance-based model of the medial ITC network (Fig. 1) with dorsal and ventral ITC modules (see Materials and Methods section). We first constructed a singlecell ITC model that could replicate the experimentally observed bistable behavior of ITC cells (Royer et al. 2000b). Short-term facilitation and depression were implemented in the GABAergic ITCITC and ITC-Ce connections, and their dynamics were adjusted to reproduce frequency-dependent changes in release probability, as observed experimentally (Geracitano et al. 2007). We first investigated whether the sustained activity seen in a single ITC cell could be maintained in the ITC network with inhibitory connectivity. Next, with experimentally observed changes in BLA firing rates and synaptic strengths, we examined how the ITC network regulated the firing of Ce neurons during fear conditioning and extinction. Finally, the model was used to study the impact of IL inputs on network activity. Note that in this section we used BLA to collectively refer to the lateral (LA) and basal (BA) nuclei of the amygdala.

\section{Single-cell firing properties}

\section{ITC model neuron}

The responses of the ITC model neuron to current injections from rest reproduced experimentally observed behaviors (Fig. 2A; Royer et al. 2000b; Marowsky et al. 2005; Geracitano et al. 2007). In response to low-amplitude depolarizing current injections (100 $\mathrm{pA})$, there was a delay to the first spike and the firing frequency gradually increased with time due to the inactivation of the $I_{\mathrm{SD}}$ current (dashed curve). Such a frequency increase with time was also observed in experimental data (see Fig. 2B in Marowsky et al. 2005). With higher current injections (200 pA), the delay to first spike was reduced and the neuron fired tonically at a higher rate. Also, the $I_{\mathrm{SD}}$ current inactivated faster compared with low-amplitude injected currents.

The impact of $I_{\mathrm{SD}}$ on the repetitive firing behavior of the ITC model neuron is shown in Figure 2B, which plots instantaneous firing frequency evoked by depolarizing current injections with (solid lines) and without (dashed lines) the $I_{\mathrm{SD}}$ current. In the presence of $I_{\mathrm{SD}}$ and with low-amplitude depolarizing current injections (100 pA, bottom), the firing frequency gradually increased. However, when the $I_{\mathrm{SD}}$ current was removed from the model, the firing frequency started at a higher rate and slowed down to about $50 \mathrm{~Hz}$ due to the activation of the $I_{\mathrm{SAHP}}$ current. Thus, the inclusion of the $I_{\mathrm{SD}}$ current changed regular frequency adaptation to reverse frequency adaptation. When the applied current increased, the firing frequency with $I_{\mathrm{SD}}$ current no longer increased monotonically with time, but showed a triphasic profile: after an initial transient increase, it decreased for about $150 \mathrm{msec}$, and then increased slightly thereafter. This indicates that with high-current injections, the $I_{\mathrm{sAHP}}$ current activated rapidly, which overcame the effect of the $I_{\mathrm{SD}}$ current inactivation in the first $200 \mathrm{msec}$. Without the $I_{\mathrm{SD}}$ current, the frequency curve also showed a similar trend, with a larger secondphase adaptation decrease due to the loss of the opposing influence from the $I_{\mathrm{SD}}$ current inactivation (Fig. $2 \mathrm{~B}$ ).

A characteristic feature of ITC cells is that due to inactivation of the $I_{\mathrm{SD}}$ current, following spike trains, they generate after-depolarizations (ADPs) that increase in amplitude with the amount of depolarizing current (Royer et al. 2000b). To test whether our model could reproduce this behavior, transient suprathreshold current injections of various amplitudes were applied from a constant pre-pulse membrane potential (Fig. 3A). With low-current injections (Fig. 3A1), the ADP had a low amplitude, and a characteristic "hump and sag" developed with increased current reaching the spike threshold (Fig. 3A2). With an even larger current, the ADP generated a burst of spikes (Fig. 3A3, reflects Fig. 2A in Royer et al. 2000b). Time-dependent variations in the activation $(m)$ and inactivation $(h)$ gating variables of the $I_{\mathrm{SD}}$ current are shown below each voltage trace in Figure 3A. As the current injection increased, the variable $h$ was inactivated to a lower level, i.e., the conductance was more efficiently reduced, thereby causing a larger ADP.

Experimentally, the ADP amplitude was reported to increase with the duration of suprathreshold depolarizing current pulses (Royer et al. 2000b). To test whether our model could reproduce this behavior, current injections of constant intensity but variable durations were applied from the same prepulse $V_{\mathrm{m}}$ (Fig. 3B). In keeping with experimental observations, the ADP amplitude increased with current pulse duration, eventually leading to spike generation (Fig. 3B3). Examination of $I_{\mathrm{SD}}$ gating variables shows 
A
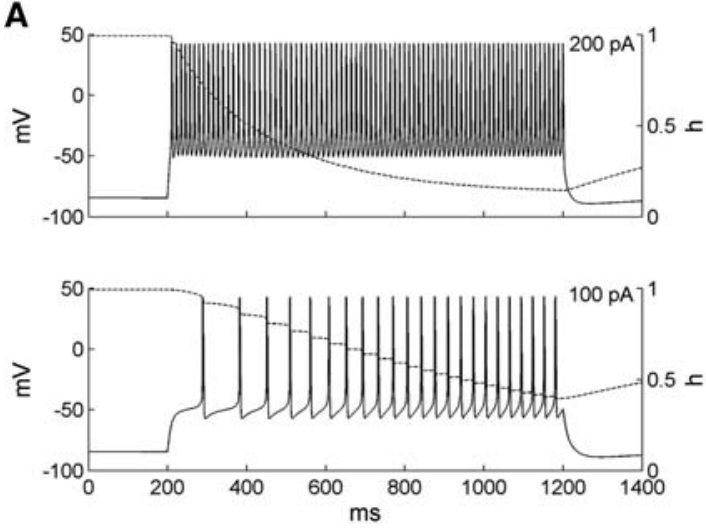

B

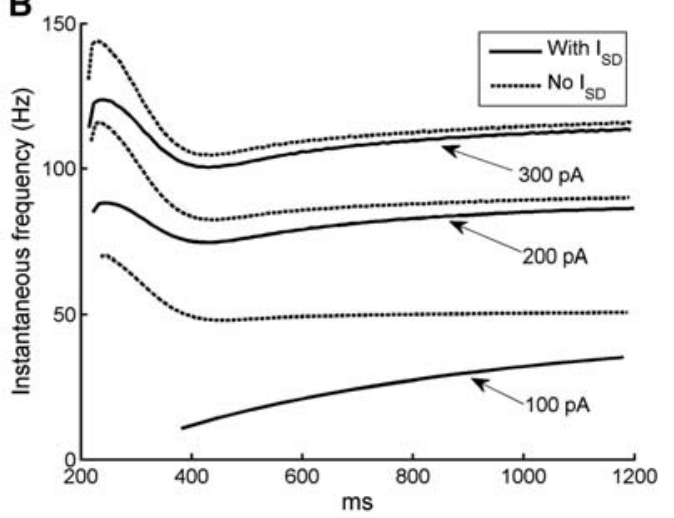

Figure 2. Firing properties of the ITC neuron model. $(A)$ Voltage responses of ITC neuron model to two 1-sec current injections from rest (top: 200 pA; bottom: $100 \mathrm{pA}$ ). Evolution of the inactivation variable $h$ of the $I_{\mathrm{SD}}$ current is shown in dash. $(B)$ Instantaneous firing frequency of ITC model to three different levels of current injections $(100,200$, and $300 \mathrm{pA})$ with $\left(g_{\mathrm{SD}}=0.06 \mathrm{mS} / \mathrm{cm}^{2}\right)$ and without $I_{\mathrm{SD}} \mathrm{current}\left(g_{\mathrm{SD}}=0 \mathrm{mS} / \mathrm{cm}^{2}\right)$.

that longer current injections inactivated the $I_{\mathrm{SD}}$ current more effectively, giving rise to larger ADPs.

Last, we examined the effect of the prepulse $V_{\mathrm{m}}$ on the ADP amplitude. Depolarizing current pulses adjusted to elicit that approximately the same number of spikes were delivered at different prepulse voltages (Fig. 3C). When $V_{\mathrm{m}}$ was low $(-75 \mathrm{mV}$ ), little ADP was produced (Fig. 3C3). An ADP was seen when $V_{\mathrm{m}}$ was depolarized to $-66 \mathrm{mV}$ (Fig. 3C2). With a more depolarized $V_{\mathrm{m}}$ $(-59 \mathrm{mV})$, the ADP resulted in tonic firing after the current pulse (Fig. 3C1), consistent with experimental observations (reflects Fig. 2B,C in Royer et al. 2000b). This was because $I_{\mathrm{SD}}$ reached its maximal activation at around $-60 \mathrm{mV}$, as found experimentally (Royer et al. 2000b; compares the activation levels of the $m$ variable before current pulses in Fig. 3C). In the sustained firing case (Fig. 3C1), the $I_{\mathrm{SD}}$ current remained inactivated for a long time, each spike renewing its inactivation.

To test that the ADP was due to the $I_{\mathrm{SD}}$ current, voltage responses to depolarizing inputs were compared under TTX condition $\left(g_{\mathrm{Na}}=0\right)$ for the whole (Fig. 3D2) and partial model without $I_{\mathrm{SD}}$ current $\left(g_{\mathrm{SD}}=0\right)$ (Fig. 3D1). So that the two conditions could be compared, the model neuron was adjusted to the same pre-pulse potential using a smaller baseline current in the no $I_{\mathrm{SD}}$ condition. When $I_{\mathrm{SD}}$ was removed from the model, the ADP was completely abolished (only AHP remained) (Fig. 3D1), demonstrating that $I_{\mathrm{SD}}$ was necessary for ADP generation.

\section{Ce model neurons}

The responses of the Ce model neurons to current injections from rest reproduced the behaviors of regular spiking (RS), late firing (LF), and low-threshold bursting (LTB) Ce cells observed experimentally (Dumont et al. 2002; De Armentia and Sah 2004). As shown in Figure 4A, with low-amplitude depolarizing current injections, the RS cell fired only one spike, whereas current pulses of higher amplitude evoked repetitive firing with modest spike frequency adaptation. Also characteristic of RS Ce neurons, negative current injection elicited a hyperpolarizing response with a slowly developing depolarizing sag, produced by the activation of $I_{\mathrm{H}}$ current. The response profiles of the LF Ce cell model to current injections are shown in Figure 4B. For a 200-pA depolarizing pulse, a long delay ( $200 \mathrm{msec}$ ) was seen for the first action potential, and the spike interval was also large. With a higher current injection $(300 \mathrm{pA})$, the initial delay was reduced and the neuron fired repetitively, consistent with experimental data (see Fig. 2B in De Armentia and Sah 2004). The firing properties of the LTB model neuron to a series of current injections are shown in Figure 4, C and D. Consistent with the experimental data (Dumont et al. 2002), the LTB model cell generated spike doublets or bursts in response to depolarizing current pulses applied negative to $-70 \mathrm{mV}$ (Fig. 4C, top two traces) and at the break of hyperpolarizing current pulses (Fig. 4D, bottom). In contrast, depolarizing current pluses applied from more positive membrane potentials elicited trains of action potentials that displayed variable degrees of frequency adaptation (Fig. 4D, top two traces).

\section{Persistent network activity}

As mentioned above, the slow deinactivation of $I_{\mathrm{SD}}$ allows ITC neurons to generate sustained depolarizations in response to transient suprathreshold current injections (Fig. 3). However, it remains unclear whether transient inputs would have the same effect in a realistic network where ITC cells are interconnected by inhibitory synapses. For instance, LA cells are known to fire transiently at CS onset (Quirk et al. 1995, 1997), yet conditioned fear responses last for the entire duration of the CS. Also, brief IL stimulation $(300 \mathrm{msec})$ was reported to effectively reduce fear expression in response to much longer CSs (Milad and Quirk 2002; Milad et al. 2004). Could $I_{\mathrm{SD}}$ allow ITC cells to transform the transient signals arising from the BLA or IL into a more persistent output? To test this, we injected a brief current pulse of 300 pA for 300 msec (red bars in Fig. 5) into all ITC cells, mimicking the transient BLA/IL signal, while more realistic adaptive BLA inputs were turned off in this model experiment. To quantify the persistent activity, the spontaneous rate was measured during the 1 sec preceding the current pulses, while the steady-state firing rate was estimated $1 \mathrm{sec}$ after the start of current injection (from 1 to $2 \mathrm{sec}$ ). Also, to test the robustness of the persistent network state, we simulated both a baseline inhibitory network (all ITCITC synaptic weights set to 2, i.e., $w_{I I}=2$ ) and a strong inhibitory network $\left(w_{I I}=5\right)$.

Figure 5, A and B, shows the voltage responses of four representative cells from the ITC $_{\mathrm{D}}\left(\mathrm{ITC}_{\mathrm{D} 1}, \mathrm{ITC}_{\mathrm{D} 10}\right)$ and $\mathrm{ITC}_{\mathrm{V}}\left(\mathrm{ITC}_{\mathrm{V} 2}\right.$, ITC $_{V 11}$ ) clusters for the control and strong inter-ITC inhibition cases, respectively. Prior to current injection, the four ITC neurons had no or little spiking activity. In both cases, current injections produced high-frequency discharges in all ITC cells. However, after the current pulse, ITC cells continued to fire at much higher rates than the spontaneous rates (Fig. 5A,B). Insights into the mechanisms underlying these phenomena can be obtained by considering time-dependent fluctuations of the $I_{\mathrm{SD}}$ inactivation variable (green lines superimposed on the voltage responses of 

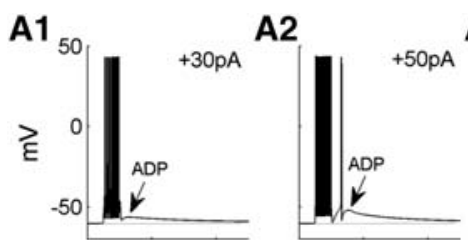

A3
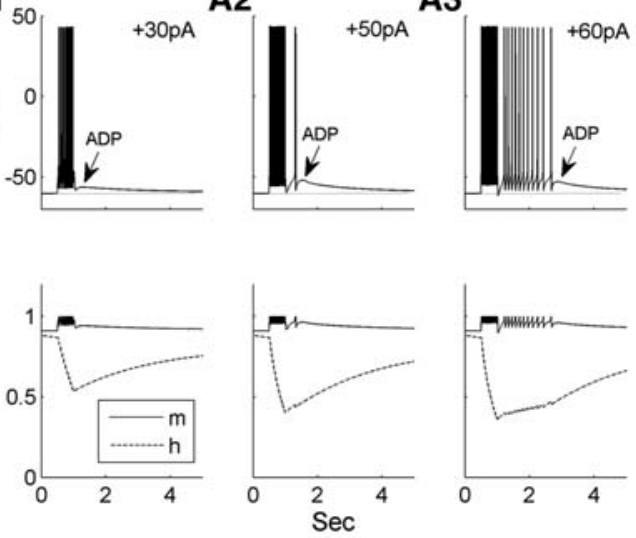

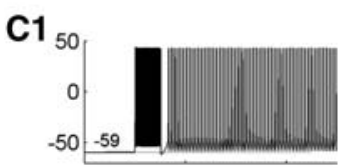

C2

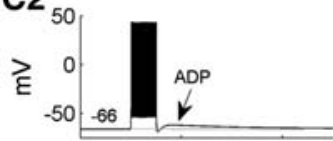

C3

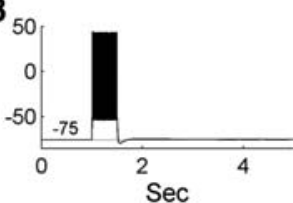

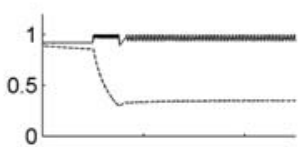
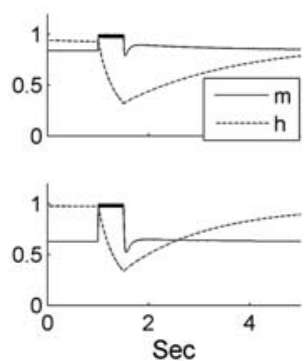

B1

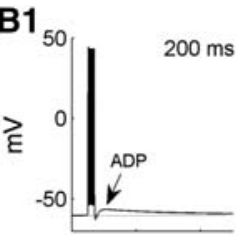

B2
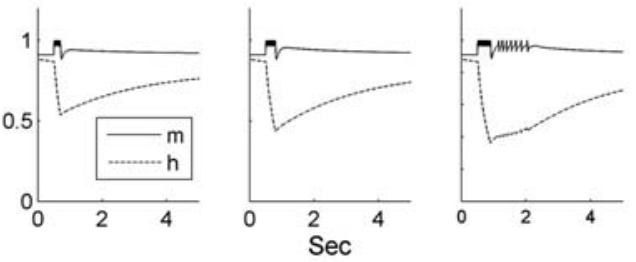

D1

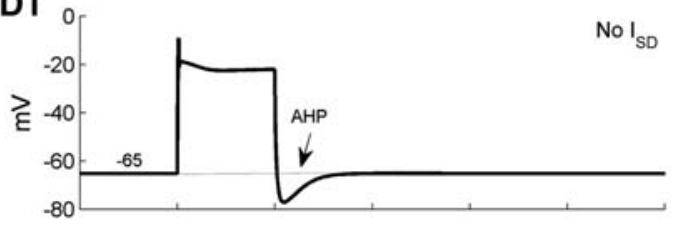

D2

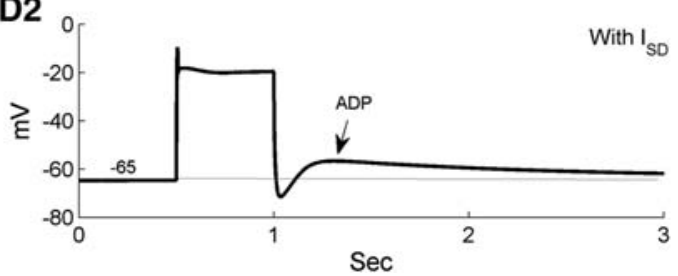

Figure 3. Bistable properties of the ITC neuron model due to the $I_{S D}$ current. (A) Dependence of the ADP on the amplitude of current injection. Transient current injections $\left(500 \mathrm{msec}\right.$ ) were applied at the same pre-pulse voltage $V_{\mathrm{m}}-60 \mathrm{mV}$ ) with different intensities (left: $30 \mathrm{pA}$; middle: $50 \mathrm{pA}$; right: $60 \mathrm{pA}$ ). The pre-pulse voltage $V_{\mathrm{m}}$ was controlled by a baseline current injection, and $m \& h$ are the activation and inactivation gating variables of the $I_{S D}$ current, respectively. (B) Dependence of the ADP on the duration of current injections. Current injections were applied at the same pre-pulse voltage $V_{\mathrm{m}}(-60 \mathrm{mV})$ and had the same amplitude. The duration of the current injection was 200,300, and $400 \mathrm{msec}$ in the left, middle, and right panels, respectively. (C) Dependence of the ADP on the pre-pulse voltage $V_{\mathrm{m}}$. Current injections $(500 \mathrm{msec}$ ) adjusted to elicit approximately the same number of spikes were applied at different $V_{\mathrm{m}}$ as indicated. $(D)$ Comparison of the entire model $\left(g_{\mathrm{SD}}=0.06 \mathrm{mS} / \mathrm{cm}^{2}\right)$ with the partial model without $I_{\mathrm{SD}}$ current $\left(g_{\mathrm{SD}}=0 \mathrm{mS} / \mathrm{cm}^{2}\right)$ in the presence of TTX $\left(g_{\mathrm{Na}}=0 \mathrm{mS} / \mathrm{cm}^{2}\right)$. The model neuron was set to the same pre-pulse potential in $D 1$ and $D 2$ by applying less depolarizing current in the no $I_{\mathrm{SD}}$ condition.

Fig. 5A,B). This reveals that $I_{\mathrm{SD}}$ inactivated rapidly during the current injection and remained inactivated thereafter $(<0.5)$. Thus, inactivation of $I_{\mathrm{SD}}$ enabled both $\mathrm{ITC}_{\mathrm{D}}$ and $\mathrm{ITC}_{\mathrm{V}}$ cells to fire continuously beyond the current injection, which in turn kept renewing the inactivation of the $I_{\mathrm{SD}}$ current. In keeping with the idea that $I_{\mathrm{SD}}$ plays a critical role in generating persistent activity, accelerating the deinactivation kinetics of $I_{\mathrm{SD}}$ abolished the persistent activity of ITC cells (Supplemental Fig. S6).

Expectedly, the impact of $I_{\mathrm{SD}}$ inactivation on persistent activity varied depending on the strength of the inhibitory connections between the ITC cells. Comparing the control (Fig. 5A) and strong inter-ITC inhibition (Fig. 5B) cases revealed that increasing inhibition strength reduced sustained activity in all four ITC cells, but only to a moderate degree. This can also be seen in Figure 5C, which plots the difference between the steadystate firing rate and spontaneous firing rate for each ITC neuron. The sustained activity of the majority of ITC cells (76.7\%) was reduced by stronger inter-ITC inhibition. A small proportion of cells (16.7\%) remained unchanged and only two cells $(6.7 \%)$ had increased activity with larger inhibitory weight. The variability was due to different number and type of inhibitory inputs received by each individual ITC cell (see Supplemental Table S3). If the reduction of firing rate in presynaptic neurons balanced or overcame the effect of increased synaptic weight, the persistent activity of post-synaptic neurons may remain unchanged or increase. This shows that increased inter-ITC coupling strength could differentially modulate the firing rates of individual ITC neurons.

The sustained activity of ITC neurons as a population can be seen by examining the instantaneous firing rates averaged on all $\mathrm{ITC}_{\mathrm{D}}$ and $\mathrm{ITC}_{\mathrm{V}}$ cells (Fig. 5D). In the control case, ITC neurons fired spontaneously at low rates to background inputs prior to current injection $\left(\mathrm{ITC}_{\mathrm{D}}: 2.7 \pm 0.7 \mathrm{~Hz}\right.$, ITC $\mathrm{V}: 1.7 \pm 0.7 \mathrm{~Hz}$; mean $\pm \mathrm{SE}$ ). After the current pulse, the average firing rate of ITC $_{D}$ increased more than fourfold (steady-state rate: $11.4 \pm 1.5 \mathrm{~Hz}$; $t$-test $P<$ 0.001 ), and that of $\mathrm{ITC}_{\mathrm{V}}$ increased nearly fourfold (steady-state rate: $6.7 \pm 1.4 \mathrm{~Hz}$; $t$-test $P<0.005)$. When the inter-ITC weight increased 2.5-fold (strong inhibition case), the spontaneous rates remained almost unchanged $\left(\right.$ ITC $_{\mathrm{D}}: 2.5 \pm 0.8 \mathrm{~Hz}$, ITC $_{\mathrm{V}}: 1.6 \pm$ $0.7 \mathrm{~Hz}, t$-test $P>0.1)$. Although reduced compared with the control case, the steady-state frequencies of $\mathrm{ITC}_{\mathrm{D}}$ and $\mathrm{ITC}_{\mathrm{V}}$ were still significantly higher than the corresponding spontaneous firing rates $\left(\right.$ ITC $_{\mathrm{D}}: 9.1 \pm 1.3 \mathrm{~Hz}$, $t$-test $P<0.001 ;$ ITC $_{\mathrm{V}}: 4.9 \pm 1.2 \mathrm{~Hz}$, $t$-test $P<0.05)$. Thus, sustained ITC network activity can be generated by transient excitatory inputs, even in the presence of strong inter-ITC inhibition. Note that in both cases, ITC $_{V}$ 
A
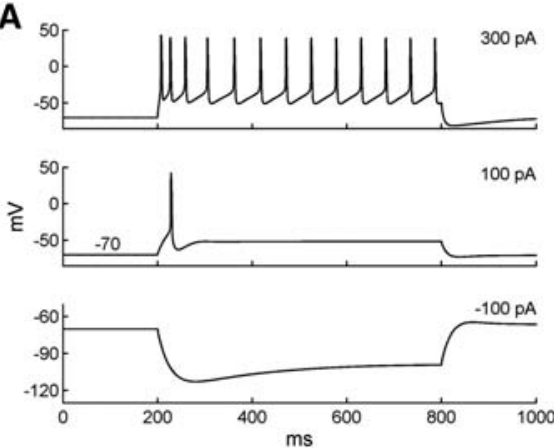

C
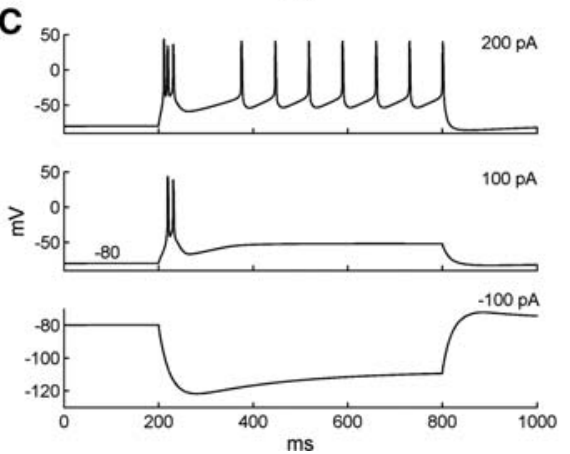

B
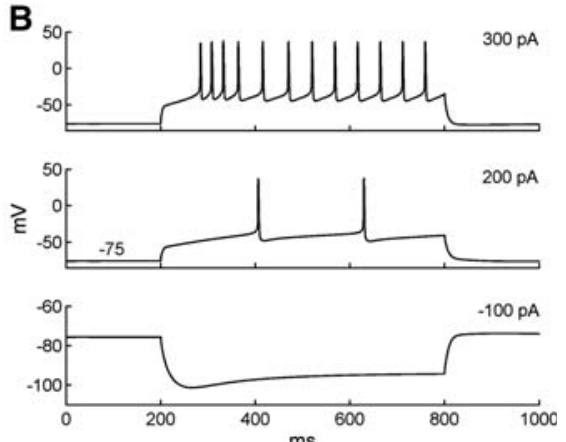

$\mathbf{D}_{50}$
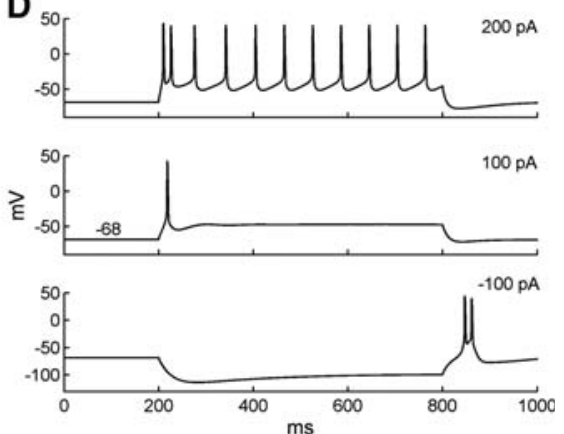

Figure 4. Firing properties of the Ce neuron models. (A) Voltage responses of the regular spiking model cell to three 600-msec current injections from rest (top: $300 \mathrm{pA}$; middle: $100 \mathrm{pA}$; bottom: $-100 \mathrm{pA})$. (B) Voltage responses of the late-firing model cell to three $600-\mathrm{msec}$ current injections from rest (top: $300 \mathrm{pA}$; middle: $200 \mathrm{pA}$; bottom: $-100 \mathrm{pA}$ ). (C) Voltage responses of the LTB neuron model to three 600 -msec current injections from $-80 \mathrm{mV}$ (top: $200 \mathrm{pA}$; middle: $100 \mathrm{pA}$; bottom: $-100 \mathrm{pA}$ ). (D) Voltage responses of the LTB neuron model to three $600-\mathrm{msec}$ current injections from rest (-68 mV; top: $200 \mathrm{pA}$; middle: $100 \mathrm{pA}$; bottom: $-100 \mathrm{pA})$.

cells exhibited less persistent activity than ITC $_{D}$ cells (the ratio of steady-state rate to spontaneous rate was lower) because of the unidirectional inhibitory connections from $\mathrm{ITC}_{\mathrm{D}}$ to $\mathrm{ITC}_{\mathrm{V}}$ neurons.

\section{Network behaviors during fear and extinction states}

Prior to studying the impact of IL inputs on ITC cells, it is important to characterize the model's behavior in response to inputs from LA and BA. Indeed, unit recordings have revealed that after fear conditioning, the responses of LA and BA neurons to CS presentations consist of an early phase of strongly increased firing frequency that quickly decays to levels slightly above baseline for the remainder of the stimulus (Quirk et al. 1995; Herry et al. 2008). It is of great interest to examine how the ITC network processes such adaptive signals to regulate the firing of Ce neurons during fear conditioning and extinction. Toward this end, we modeled three separate network states (habituation, following fear conditioning, and after extinction training) with experimentally observed LA/ BA firing rates and synaptic plasticity. Previous experimental work has revealed that expression of fear is a result of potentiated LA responses to the CS (Quirk et al. 1995) relayed to Ce via BA (Pitkanen 2000) and ITC cells (Pare et al. 2004; Pape and Pare 2010), while extinction is accompanied by diminished LA responses (Quirk et al. 1995). A recent experimental study (Herry et al. 2008) reported that BA contains three subpopulations of neurons whose CS responsiveness is differentially altered during fear conditioning and extinction training: "fear cells" that acquire CS responses as a result of fear conditioning, but lose them following extinction training; "extinction cells" that only become CS responsive following extinction training; and "extinction-resistant cells" that acquire CS responses during

conditioning, but remain CS responsive after extinction training. Accordingly, the fear state was modeled with elevated firing rate of $\mathrm{LA}, \mathrm{BA}$ fear $\left(\mathrm{BA}_{\mathrm{F}}\right)$, and extinction-resistant $\left(\mathrm{BA}_{\mathrm{ER}}\right)$ neurons, while the extinction state was modeled with diminished $\mathrm{LA}$ and $\mathrm{BA}_{\mathrm{F}}$ inputs, plus increased firing rate of $\mathrm{BA}$ extinction $\left(\mathrm{BA}_{\mathrm{E}}\right)$ neurons (see Supplemental Materials section for details). Different synaptic weights were also given for certain synapses in the three network states (Table 1; see Materials and Methods section for details). As indicated in the Materials and Methods section, we considered two possible network architectures with all BA inputs projecting to ITC cells in the first architecture and only extinction inputs projecting to ITC cells in the second architecture. In both architectures, the extinction neurons did not project to Ce because the activation profile of extinction cells was opposite to the expression of fear (Herry et al. 2008). Instead, both fear and extinction-resistant inputs projected to Ce.

Below, we describe the performance of each of the architectures. In these model experiments, we used several terms of firing frequency defined as follows. When a 2 -sec CS input was present, the steady-state firing frequency was measured during the last $1 \mathrm{sec}$ of the $\mathrm{CS}$, while the estimate of the CS-induced frequency was based on the entire 2-sec CS period. The instantaneous firing frequency was calculated by dividing the simulation time into 100-msec bins, and the spontaneous firing rate was measured during the 1 -sec period prior to CS onset.

\section{Architecture 1}

The instantaneous frequency of $\mathrm{LA}, \mathrm{BA}_{\mathrm{F}}, \mathrm{BA}_{\mathrm{ER}}$, and $\mathrm{BA}_{\mathrm{E}}$ inputs during CS presentation in three network states is shown in Figure 6A, while that of $\mathrm{ITC}_{\mathrm{D}}, \mathrm{ITC}_{\mathrm{V}}$, and Ce neurons is shown in Figure $6 \mathrm{~B}$. The change in CS-induced neuronal firing rate across behavioral states is summarized in Table 2. The steady-state (SS) frequency is also given for Ce. Frequency is given as mean \pm SEM. At rest with random background inputs, the average spontaneous firing rates of $\mathrm{ITC}_{\mathrm{D}}$, ITC $\mathrm{V}$, and Ce cells were $2.7 \pm 0.7 \mathrm{~Hz}, 1.7 \pm 0.7 \mathrm{~Hz}$, and $2.2 \pm 0.4 \mathrm{~Hz}$, respectively (the Ce rate was based on Duvarci et al. 2011). In habituation, the LA and BA inputs were delivered at low frequency (LA: $3.0 \pm 0.1 \mathrm{~Hz}, \mathrm{BA}_{\mathrm{F}}: 1.8 \pm 0.1 \mathrm{~Hz}, \mathrm{BA}_{\mathrm{ER}}$ : $1.55 \pm 0.05 \mathrm{~Hz}$, and $\mathrm{BA}_{\mathrm{E}}: 1.6 \pm 0.2 \mathrm{~Hz}$; mean $\pm \mathrm{SE}$, average over the $\mathrm{CS}$ ). The firing pattern of $\mathrm{BA}_{\mathrm{F}}$ and $\mathrm{BA} \mathrm{ER}_{\mathrm{ER}}$ inputs was similar to that of LA inputs, which showed strong frequency adaptation (Fig. 6A). Due to extra LA inputs and the unidirectional inhibition from ITC $_{D}$ to ITC $C_{V}$, the ITC $C_{D}$ neurons fired at a higher frequency than ITC $_{\mathrm{V}}$ neurons $(14.3 \pm 2.2 \mathrm{~Hz}$ vs. $4.2 \pm 1.4 \mathrm{~Hz}$, $t$-test $P<$ 0.001 , average over the CS). The Ce showed elevated firing in the first $100 \mathrm{msec}$ of CS, which adapted quickly to baseline level (Fig. 6B). Though the average CS-evoked Ce firing rate $(3.4 \pm$ $0.6 \mathrm{~Hz}$, $t$-test $P>0.1$ ) was slightly higher than the average spontaneous rate $(2.2 \pm 0.4 \mathrm{~Hz})$, the steady-state frequency was slightly lower $(1.6 \pm 0.9 \mathrm{~Hz}, t$-test $P>0.1)$. The early Ce response to CS simulated the animal's natural reaction to a neutral stimulus. 
A

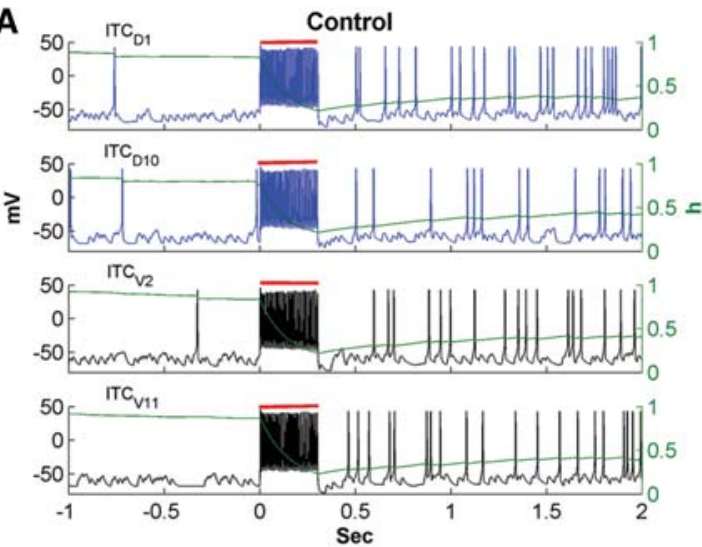

C

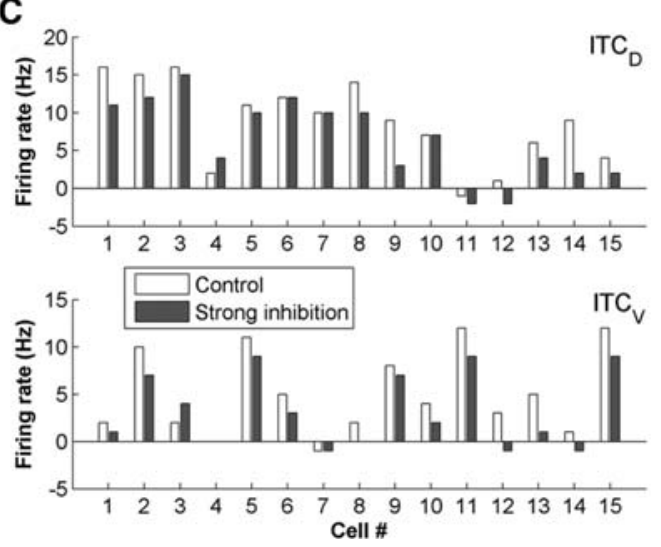

B
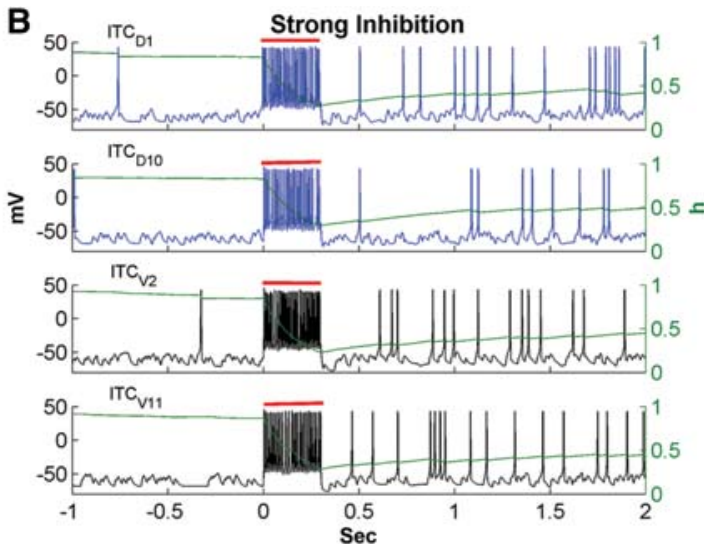

D
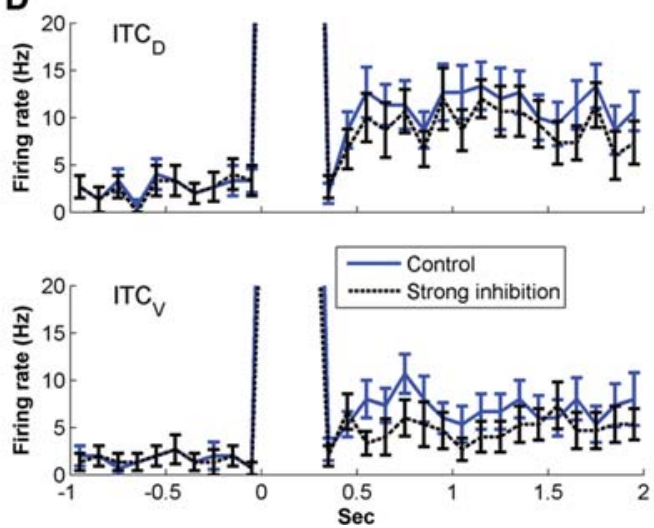

Figure 5. Persistent network activity elicited by transient excitatory inputs. $(A, B)$ Voltage responses of ITC $C_{D 1}$, ITC $C_{D 10}$, ITC $C_{V 2}$, and ITC $C_{V 11}$ for the control $\left(w_{\|}=2 ; A\right)$ and strong inter-ITC inhibition $\left(w_{\|}=5 ; B\right)$ cases. Evolution of the inactivation variable $(h)$ of the $I_{\mathrm{SD}}$ Current is shown in green. The red bars indicate the duration of the transient input. (C) Difference between the steady-state firing rate and spontaneous rate of individual ITC $C_{D}$ and ITC $C_{V}$ neurons. (D) Instantaneous firing frequency of ITC $C_{D}$ and ITC $C_{V}$ neurons as a population. Error bars indicate SEM and bin width is 100 msec; same in Figure 6.

In the fear state, the CS-induced firing frequencies of $\mathrm{LA}, \mathrm{BA}$, and $\mathrm{BA}_{\mathrm{ER}}$ were greatly increased (LA: $8.4 \pm 0.4 \mathrm{~Hz}, \mathrm{BA}_{\mathrm{F}}: 4.9 \pm$ $0.3 \mathrm{~Hz}, \mathrm{BA}_{\mathrm{ER}}: 4.2 \pm 0.3 \mathrm{~Hz}$, $t$-test $\left.P<0.001\right)$, while that of $\mathrm{BA}_{\mathrm{E}}$ remained the same $(1.7 \pm 0.2 \mathrm{~Hz}$, $t$-test $P>0.1)$ (Fig. $6 \mathrm{~A})$. With potentiation of the LA-ITC $\mathrm{D}_{\mathrm{D}}$ synapses (Table 1), the CS-induced firing rate of $\mathrm{ITC}_{\mathrm{D}}$ cells greatly increased from $14.3 \pm 2.2 \mathrm{~Hz}$ to $35.2 \pm 4.1 \mathrm{~Hz}$ ( $t$-test $P<0.001)$, while that of ITC $_{\mathrm{V}}$ cells slightly decreased from $4.2 \pm 1.4 \mathrm{~Hz}$ to $3.9 \pm 1.4 \mathrm{~Hz}$ ( $t$-test $P>0.1$ ). This was because the enhanced inhibition from ITC $_{D}$ overcame the elevated drive from $B A_{F}$ and $B A_{E R}$ inputs to $I_{T} C_{V}$ cells. With increase of the $\mathrm{BA}_{\mathrm{F}}$ and $\mathrm{B} \mathrm{A}_{\mathrm{ER}}$ firing rate combined with disinhibition from $\mathrm{ITC}_{V}$ cells, the CS-evoked discharge frequency of the Ce output greatly increased from $3.4 \pm 0.6 \mathrm{~Hz}$ to $9.7 \pm 0.8 \mathrm{~Hz}$ ( $t$-test $P<0.001$ ) (Fig. 6B), signaling a high "fear" state. The initial frequency in the first bin could even reach above $30 \mathrm{~Hz}$ (Fig. 6B) due to high frequency of BA inputs in the first $100 \mathrm{msec}$. The average steady-state frequency $(8.4 \pm 0.8 \mathrm{~Hz})$ was also significantly higher than the average spontaneous firing rate $(2.2 \pm 0.4 \mathrm{~Hz}$, $t$-test $P<0.001)$, indicating a persistent state of fear during the entire CS presentation. It should be noted that the $8-10 \mathrm{~Hz}$ firing rate of $\mathrm{Ce}$ in the fear state is consistent with experimental data (unpublished observations from the Pare lab). To compare the amount of spike frequency adaptation in LA/BA inputs and ITC neurons, we computed the quantity $F_{\text {adap}}$, proposed by Wang (1998): $F_{\text {adap }}=\left(f_{0}-f_{\mathrm{ss}}\right) / f_{0}$, where $f_{0}$ is the initial firing rate (frequency in the first bin) and $f_{\text {ss }}$ is the steady-state firing rate (frequency during the last $1 \mathrm{sec}$ of $\mathrm{CS}$ ). This revealed that adaptation was much higher in LA/BA inputs (LA: $80.8 \%, \mathrm{BA}_{\mathrm{F}}: 84 \%$,
BAER: $_{\text {ER }}$ 79.3\%) than in ITC cells (ITC ${ }_{D}: 51.0 \%$, ITC $_{V}: 21.4 \%$ ). Thus, the strongly adapting signals from BLA neurons can be transformed into a more-sustained, less-adaptive output by ITC cells. The Ce output also exhibited less frequency adaptation compared with BLA inputs in the fear state (75.3\%).

In the extinction state, the CS-induced firing rates of LA and $\mathrm{BA}_{\mathrm{F}}$ inputs returned back to the habituation level (LA: $3.0 \pm$ $0.1 \mathrm{~Hz}, \mathrm{BA}_{\mathrm{F}}: 1.7 \pm 0.1 \mathrm{~Hz}$, $t$-test $P>0.1$ ), while that of $\mathrm{BA}_{\mathrm{ER}}$ inputs remained as high as the fear state $(4.1 \pm 0.2 \mathrm{~Hz}$, $t$-test $P>0.1)$ (Fig. 6A). Also, the $\mathrm{BA}_{\mathrm{E}}$ inputs switched on with adaptation $(3.6 \pm 0.4 \mathrm{~Hz}, t$-test $P<0.002$, average over the CS). Due to decrease in LA firing rate with partial depotentiation of the LAITC $_{\mathrm{D}}$ synapses (Table 1), the drive from LA to ITC $_{\mathrm{D}}$ was largely reduced. At the same time, the excitation from BA inputs to ITC $_{D}$ increased as the BA-ITC synaptic strength was potentiated (decrease in $\mathrm{BA}_{\mathrm{F}}$ firing rate was compensated by increase in $\mathrm{BA}_{\mathrm{E}}$ firing rate). Since the decrease in LA drive overwhelmed the increase in BA excitation, the CS-evoked firing rate of ITC $_{D}$ was reduced from $35.2 \pm 4.1 \mathrm{~Hz}$ (in fear state) to $22.7 \pm 2.7 \mathrm{~Hz}$ (t-test $P<$

Table 1. Synaptic weights used in the ITC network model during the three network states

\begin{tabular}{|c|c|c|c|c|c|}
\hline & $\mathrm{LA} \rightarrow \mathrm{ITCD}$ & $\underset{\mathrm{ITCD} / \mathrm{V}}{\mathrm{BA} \rightarrow}$ & $\mathrm{BA} \rightarrow \mathrm{Ce}$ & $\begin{array}{l}\mathrm{ITCD} / \mathrm{V} \rightarrow \\
\operatorname{ITCD} / \mathrm{V}\end{array}$ & $\mathrm{ITCV} \rightarrow \mathrm{Ce}$ \\
\hline Habituation & 1 & 1 & 2 & 2 & 5 \\
\hline Fear & 3 & 1 & 2 & 2 & 5 \\
\hline Extinction & 2 & 3 & 2 & 2 & 5 \\
\hline
\end{tabular}


A

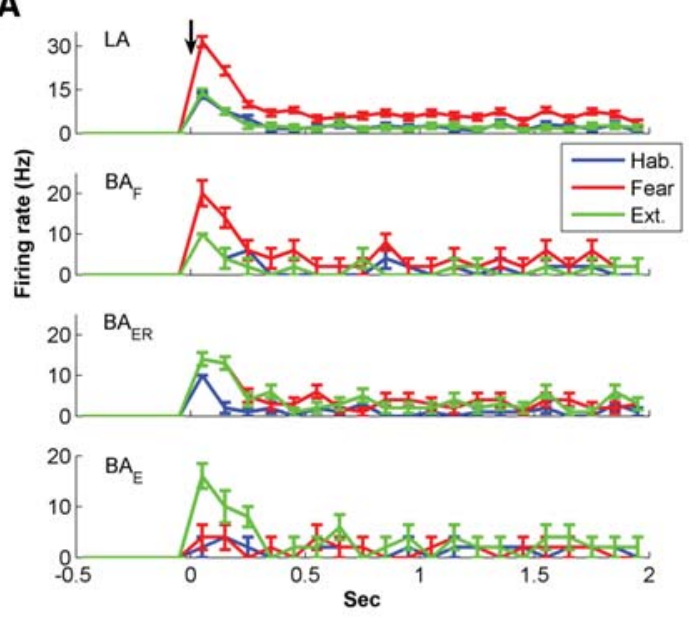

C
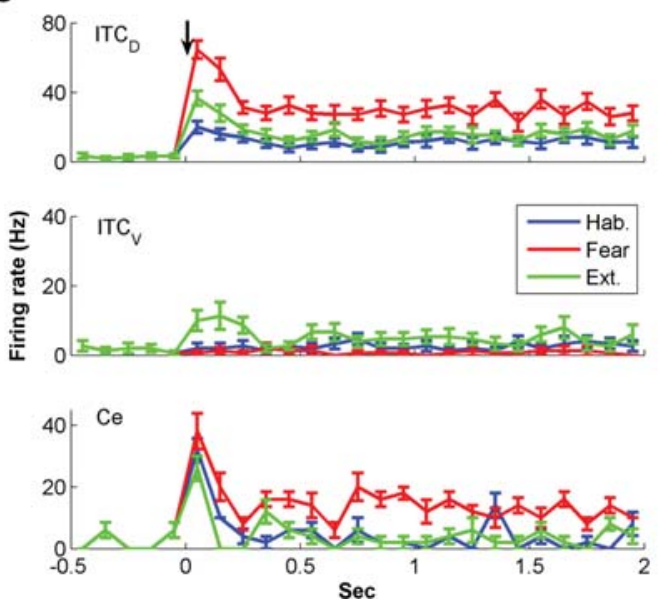

B
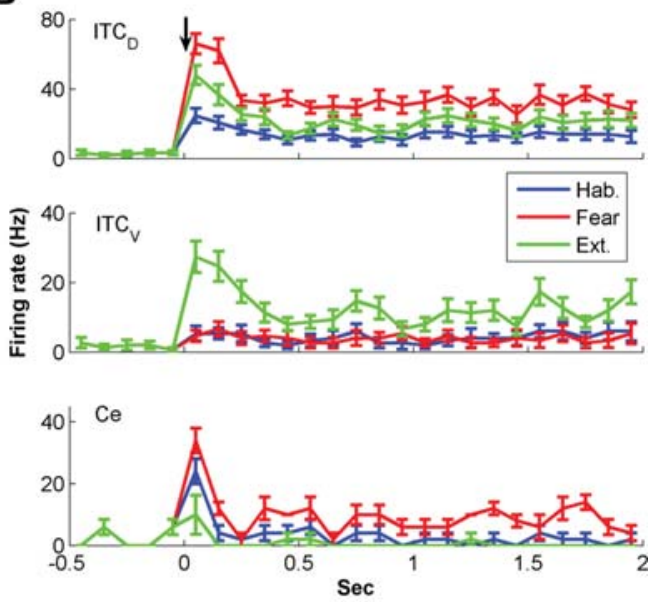

D
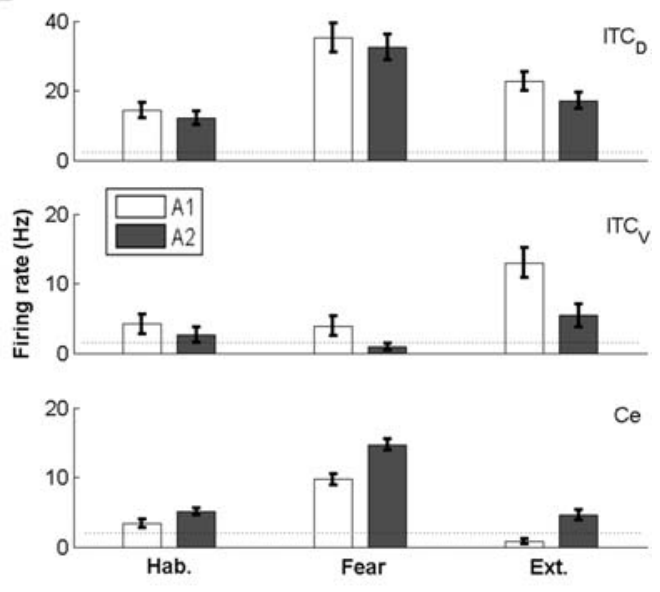

Figure 6. Network behaviors during habituation, fear, and extinction states without IL inputs. $(A)$ Instantaneous firing frequency of LA and BA inputs. (B) Instantaneous firing frequency of ITC $C_{D}, I T C_{V}$, and Ce neurons for architecture 1. (C) Instantaneous firing frequency of ITC $D$, ITC $C_{V}$, and Ce neurons for architecture 2. The black arrows indicate CS onset. $(D)$ Average CS-evoked firing frequencies of ITC $C_{D}, I T C_{V}$, and Ce neurons for architectures 1 and 2. The dotted lines indicate the spontaneous firing rates.

0.02) (Fig. 6B). The reduction of inhibition from $I_{T} C_{D}$ plus potentiation of BA inputs led to a large increase in the CS-evoked ITC $_{V}$ firing rate (from $3.9 \pm 1.4 \mathrm{~Hz}$ to $13.0 \pm 2.1 \mathrm{~Hz}$, $t$-test $P<$ 0.002) (Fig. 6B), imposing a large inhibition on Ce. On the other hand, the excitatory drive from $\mathrm{BA}$ to Ce decreased with extinguished $\mathrm{BA}_{\mathrm{F}}$ inputs (Fig. 6A). As a result of increased inhibition with decreased excitation, the CS-evoked discharge rate of Ce neurons went below the average spontaneous rate $(0.8 \pm 0.4 \mathrm{~Hz}$, $t$-test $P<0.05$ ) (Fig. 6B). In this state, the percentages of adaption in LA/BA inputs (LA: 85\%, BA $: 88 \%, \mathrm{BA}_{\mathrm{ER}}: 78.6 \%, \mathrm{BA}_{\mathrm{E}}: 86.3 \%$ ) were also much higher than those in ITC cells (ITC $\mathrm{D}: 54.9 \%$, ITC $\left._{\mathrm{V}}: 56.6 \%\right)$. Model experiments also revealed that changing all ITC synapses to the depressing type impaired extinction, while using only the facilitating or constant types had little effect on network activity (Supplemental Fig. S7).

\section{Architecture 2}

In architecture 2, the $\mathrm{BA}_{\mathrm{F}}$ and $\mathrm{BA}_{\mathrm{ER}}$ inputs did not project to ITC. For ease of comparison, we denote architecture 1 as "A1" and architecture 2 as "A2". The instantaneous firing rate of ITC $_{D}$, ITC , and Ce neurons is shown in Figure $6 \mathrm{C}$, and the average frequency over the entire CS for A1 and A2 is compared in Figure $6 \mathrm{D}$. The change in CS-induced neuronal firing rate across behavioral states is also summarized in Table 2. In habituation, removal of $\mathrm{BA}_{\mathrm{F}}$ and $\mathrm{BA}_{\mathrm{ER}}$ inputs to ITC only decreased the CS-induced firing rate of ITC $_{\mathrm{D}}$ by $15.4 \%$ (A1: $14.3 \pm 2.2 \mathrm{~Hz}, \mathrm{~A} 2$ : $12.1 \pm 1.9 \mathrm{~Hz}$, $t$-test $P>0.1$ ) (Fig. 6D) since LA inputs still projected to ITC $_{D}$ and were the dominant source of ITC $_{D}$ excitation. In contrast, the CS-induced ITC $_{V}$ firing rate was reduced by $38.1 \%$ (A1: $4.2 \pm 1.4 \mathrm{~Hz}, \quad \mathrm{~A} 2: 2.6 \pm 1.1 \mathrm{~Hz}$, $t$-test $P>0.1$ ) (Fig. $6 \mathrm{D}$ ).
Table 2. Spontaneous and CS-induced firing rates $(\mathrm{Hz})$ of ITC and $\mathrm{Ce}$ neurons in three network states for architecture 1 (A1) and architecture 2 (A2)

\begin{tabular}{|c|c|c|c|c|c|c|c|}
\hline & \multirow[b]{2}{*}{ Spont. } & \multicolumn{2}{|c|}{ Hab. } & \multicolumn{2}{|c|}{ Fear } & \multicolumn{2}{|c|}{ Ext. } \\
\hline & & $\mathrm{A} 1$ & $\mathrm{~A} 2$ & A1 & $\mathrm{A} 2$ & A1 & A2 \\
\hline$I T C_{D}$ & $2.7 \pm 0.7$ & $14.3 \pm 2.2$ & $12.1 \pm 1.9$ & $35.2 \pm 4.1$ & $32.5 \pm 3.7$ & $22.7 \pm 2.7$ & $17.1 \pm 2.3$ \\
\hline $\mathrm{ITC} \mathrm{V}_{\mathrm{V}}$ & $1.7 \pm 0.7$ & $4.2 \pm 1.4$ & $2.6 \pm 1.1$ & $3.9 \pm 1.4$ & $0.9 \pm 0.5$ & $13.0 \pm 2.1$ & $5.4 \pm 1.6$ \\
\hline $\mathrm{Ce}$ & $2.2 \pm 0.4$ & $3.4 \pm 0.6$ & $5.1 \pm 0.5$ & $9.7 \pm 0.8$ & $14.7 \pm 0.8$ & $0.8 \pm 0.4$ & $4.6 \pm 0.7$ \\
\hline $\mathrm{Ce}(\mathrm{SS})$ & $2.2 \pm 0.4$ & $1.6 \pm 0.9$ & $3.2 \pm 0.6$ & $8.4 \pm 0.8$ & $12.2 \pm 0.6$ & $0.2 \pm 0.2$ & $3.6 \pm 0.9$ \\
\hline
\end{tabular}


The CS-evoked firing rate of Ce was elevated to $5.1 \pm 0.5 \mathrm{~Hz}$ (A1: $3.4 \pm 0.6 \mathrm{~Hz}$, $t$-test $P<0.1$ ) (Fig. $6 \mathrm{D}$ ) and showed a high response in the first $100 \mathrm{msec}$ (Fig. 6C). It should be noted that this firing rate of $\mathrm{Ce}(5.1 \pm 0.5 \mathrm{~Hz})$ was significantly higher than the average spontaneous rate $(2.2 \pm 0.4 \mathrm{~Hz}$, $t$-test $P<0.002)$ (Fig. $6 \mathrm{D})$, implying that the animal expresses fear in habituation, which is not true. Similarly, in the fear state, removing $\mathrm{BA}_{\mathrm{F}}$ and $\mathrm{BA}_{\mathrm{ER}}$ inputs to ITC had a much larger impact on $\operatorname{ITC}_{V}(76.9 \%$ decrease, A1: $3.9 \pm 1.4 \mathrm{~Hz}, \mathrm{~A} 2: 0.9 \pm 0.5 \mathrm{~Hz}, t$-test $P<0.05$, CS-evoked rate) than on ITC $_{D}(7.7 \%$ decrease, A1: $35.2 \pm 4.1 \mathrm{~Hz}, \mathrm{~A} 2: 32.5 \pm$ $3.7 \mathrm{~Hz}$, $t$-test $P>0.1$, CS-evoked rate) (Fig. 6D). As a result, the CS-induced Ce firing rate was increased by $51.6 \%$ (A1: $9.7 \pm$ $0.8 \mathrm{~Hz}, \mathrm{~A} 2: 14.7 \pm 0.8 \mathrm{~Hz}$, $t$-test $P<0.005$ ) (Fig. 6D). Thus, less BA inputs to ITC would facilitate expression of fear. In the extinction state, loss of $\mathrm{BA}_{\mathrm{F}}$ and $\mathrm{BA}_{\mathrm{ER}}$ inputs to ITC decreased the CSinduced ITC $_{\mathrm{D}}$ firing rate by $24.7 \%(\mathrm{~A} 1: 22.7 \pm 2.7 \mathrm{~Hz}, \mathrm{~A} 2: 17.1 \pm$ $2.3 \mathrm{~Hz}, t$-test $P>0.1$ ) and the $\mathrm{ITC}_{\mathrm{V}}$ firing rate by $58.5 \%$ (A1: $13.0 \pm 2.1 \mathrm{~Hz}, \mathrm{~A} 2: 5.4 \pm 1.6 \mathrm{~Hz}$, $t$-test $P<0.01$ ) (Fig. 6D). Such a large decrease in $\mathrm{ITC}_{\mathrm{V}}$ firing rate resulted in a near sixfold increase in the CS-evoked Ce firing rate $(\mathrm{A} 1: 0.8 \pm 0.4 \mathrm{~Hz}, \mathrm{~A} 2: 4.6 \pm 0.7 \mathrm{~Hz}$, $t$-test $P<0.002$ ) (Fig. 6D). Extinction in architecture 2 was thus not complete because this level of firing rate $(4.6 \pm 0.7 \mathrm{~Hz})$ was also significantly higher than the average spontaneous rate $(2.2 \pm 0.4 \mathrm{~Hz}$, $t$-test $P<0.02)$. Taken together, the firing rate of ITC $_{V}$ cells was largely decreased, while that of Ce cells was significantly increased in architecture 2 . Since such high Ce firing rates were not observed in experiments (Duvarci et al. 2011), we reasoned that the architecture 1 is more realistic.

\section{Impact of IL inputs in network conditions reproducing a high fear state}

Brief IL stimulation after tone onset (100-400 msec) has been reported to effectively reduce fear in rats that had not been extinguished (Milad and Quirk 2002), but had less or little effect if given either $1 \mathrm{sec}$ before or $1 \mathrm{sec}$ after tone onset (Milad et al. 2004). It is not clear how such a transient IL input can reduce fear effectively and why it is most effective if delivered shortly after tone onset. To investigate this, brief IL stimulation (300 msec) was modeled by Poisson-distributed spike trains $(20 \mathrm{~Hz})$ delivered to ITC neurons $0.1 \mathrm{sec}$ after tone onset (Fig. 7B), $1 \mathrm{sec}$ before tone onset (Fig. 7C), and $1 \mathrm{sec}$ after tone onset (Fig. 7D) during the high fear state (the IL-ITC synaptic weight was set to 1). For comparison, the baseline network activity in the high fear state (without IL stimulation) is shown in Figure 7A. In each figure, we plotted a 3-sec neuronal activity for two representative ITC $_{D}$ cells $\left(\right.$ ITC $\left._{\mathrm{D} 1}, \mathrm{ITC}_{\mathrm{D} 10}\right)$, two representative $\mathrm{ITC}_{\mathrm{V}}$ cells $\left(\mathrm{ITC}_{\mathrm{V} 2}\right.$, ITC $_{\mathrm{V} 11}$ ), and two Ce cells (one LF and one LTB). Since we inferred that architecture 1 was closer to the realism from previous simulation, we used architecture 1 for this IL experiment.

IL stimulation caused a large increase in the firing rates of both $\mathrm{ITC}_{\mathrm{D}}$ and $\mathrm{ITC}_{\mathrm{V}}$ neurons, which completely eliminated Ce firing during the $300 \mathrm{msec}$ IL presentation (indicated by the red bars, Fig. 7B-D). It should be noted that this reduction in CS-related Ce responses to BLA inputs is consistent with earlier experimental observations (Quirk et al. 2003). However, the effect of IL was not restricted to the 300 -msec presentation, as it could facilitate ITC firing beyond the stimulation period due to the persistent inactivation of $I_{\mathrm{SD}}$. Indeed, neuron $\mathrm{ITC}_{\mathrm{V} 2}$ fired only three action potentials during the 3 -sec period in the fear state (Fig. 7A), but fired continuously after IL stimulation (Fig. 7B-D). Such facilitating effect was also evident in neuron ITC $_{V 11}$. Compared with ITC $_{\mathrm{V} 2}$ and ITC $_{\mathrm{V} 11}$, the facilitating effect of IL on the two ITC $_{\mathrm{D}}$ cells $\left(\mathrm{ITC}_{\mathrm{D} 1}\right.$ and $\left.\mathrm{ITC}_{\mathrm{D} 10}\right)$ was much smaller, because these cells already discharged at relatively high frequency in the absence of IL inputs, inactivating the $I_{\mathrm{SD}}$ current effectively. As a result, IL stimulation caused little further inactivation of $I_{\mathrm{SD}}$. Thus, the brief IL input modulated individual ITC firing differentially, depending on their firing rates. In the high fear state, $\mathrm{ITC}_{\mathrm{V}}$ neurons fired at rates much lower than $\mathrm{ITC}_{\mathrm{D}}$ neurons $(3.9 \pm 1.4 \mathrm{~Hz}$ vs. $35.2 \pm$ $4.1 \mathrm{~Hz}$, $t$-test $P<0.001$, CS-evoked rate) due to the potentiation of LA inputs and the unidirectional inhibitory connections from ITC $_{D}$ to ITC $V$ cells. Hence, the facilitating effect of IL stimulation on $\mathrm{ITC}_{\mathrm{V}}$ neurons was greater than that on $\mathrm{ITC}_{\mathrm{D}}$ cells. Indeed, in the case of IL $+0.1 \mathrm{sec}$, IL stimulation caused a $43.2 \%$ increase in the steady-state firing frequency of ITC $_{V}$ neurons (from $3.7 \pm 1.4 \mathrm{~Hz}$ to $5.3 \pm 1.6 \mathrm{~Hz}$, $t$-test $P>0.1$ ), compared with only a $1.2 \%$ increase in ITC $_{\mathrm{D}}$ cells (from $32.3 \pm 4.1 \mathrm{~Hz}$ to $32.7 \pm 4.1 \mathrm{~Hz}$, $t$-test $P>0.1$ ). Such an increase in ITC $_{V}$ activity decreased the Ce steady-state firing rate from $8.4 \pm 0.8 \mathrm{~Hz}$ to $4.0 \pm 1.2 \mathrm{~Hz}$ ( $t$-test $P<0.02$; Fig. 7 , cf. A and B).

To compare the IL effectiveness in three cases of IL timing, we denote the effect during the 300-msec IL presentation as "direct effect" and the effect after IL stimulation as "facilitating effect". As shown in Figure 7, B-D, the direct effect was always stronger than the facilitating effect. Although IL inputs delivered $1 \mathrm{sec}$ before tone onset could still enhance the CS responses of $\mathrm{ITC}_{\mathrm{V}}$ neurons due to the slow deinactivation kinetics of the $I_{\mathrm{SD}}$ current, the direct effect was lost during the CS presentation so the facilitating effect was also reduced (Fig. 7, cf. B and C). Indeed, the average steady-state frequency of ITC $\mathrm{V}_{\mathrm{V}}$ in the IL +0.1 case was higher than that in the IL -1 sec case $(5.3 \pm 1.6 \mathrm{~Hz}$ vs. $4.8 \pm 1.5 \mathrm{~Hz}$, $t$-test $P>0.1$ ). If IL stimulation was given $1 \mathrm{sec}$ after tone onset, its impact was much reduced because it could not inhibit the Ce firing during the first $1 \mathrm{sec}$ of CS where high frequency of Ce spikes were present (Fig. 7D). Figure 7E plots the percentage change in the average firing frequency of ITC $_{\mathrm{D}}$, ITC $\mathrm{V}$, and Ce neurons during the 2-sec CS presentation for the three IL stimulation cases (Fig. 7B-D) relative to the fear case (Fig. 7A). The average Ce firing rate was reduced by $51.6 \%$ for the $\mathrm{IL}+0.1 \mathrm{sec}$ case (from $9.7 \pm$ $0.8 \mathrm{~Hz}$ to $4.7 \pm 0.7 \mathrm{~Hz}$, $t$-test $P<0.005$ ), compared with $43.3 \%$ for the IL $-1 \mathrm{sec}$ case (from $9.7 \pm 0.8 \mathrm{~Hz}$ to $5.5 \pm 0.8 \mathrm{~Hz}$, $t$-test $P<0.01$ ), and $35.1 \%$ for the IL $+1 \mathrm{sec}$ case (from $9.7 \pm 0.8 \mathrm{~Hz}$ to $6.3 \pm 0.8 \mathrm{~Hz}$, $t$-test $P<0.02$ ). This is consistent with the experimental finding that IL stimulation given $0.1 \mathrm{sec}$ after CS onset is most effective in reducing fear expression, followed by IL -1 sec and then IL $+1 \mathrm{sec}$ (Milad et al. 2004). It can be predicted that if IL stimulation is given at tone onset, fear can be further reduced, since IL inputs can eliminate the Ce burst firing in the first 100 msec. When the strength of IL stimulation increased, little further reduction was seen in the Ce firing frequency (for the case of IL + $0.1 \mathrm{sec}$; Supplemental Fig. S8), suggesting that low intensity of IL stimulation was as effective as high intensity of IL stimulation (Milad et al. 2004). It should also be noted that the LTB Ce cell fired at a higher rate than the LF Ce cell during CS presentation in the fear state $(11 \mathrm{~Hz}$ vs. $7 \mathrm{~Hz})$ (Fig. 7A) and was more resistant to IL-induced inhibition (Fig. 7B-D), probably due to partial deinactivation the $I_{\mathrm{CaT}}$ current by hyperpolarization.

Setting all inter-ITC synapses to one particular type had little effect in the fear state due to the low firing rate of ITC $_{V}$ neurons (Supplemental Fig. S7). In contrast, when IL inputs were introduced (0.1 sec after CS onset), clear differences were seen as a function of inter-ITC synapse types (Fig. 7F). When all ITC synapses were of the facilitating or constant types (including the ITC-Ce synapses), both ITC $_{\mathrm{D}}$ and $\mathrm{ITC}_{\mathrm{V}}$ firing rates (CS-evoked) decreased as inter-ITC inhibitory efficiency increased. The percentage of decrease was similar for the two cases $\left(\right.$ ITC $_{\mathrm{D}}$ : $\sim 4 \%$, ITC $_{V}$ : $\sim 13 \%$ ) (Fig. $7 F$ ). Since ITC cells projecting to Ce only form synapses of the facilitating and constant types (Geracitano et al. 2007), changing them all to the facilitating or constant types had little effect on their efficiency (see Supplemental Fig. S4, the release probability of facilitating synapses at high rates was about 
A

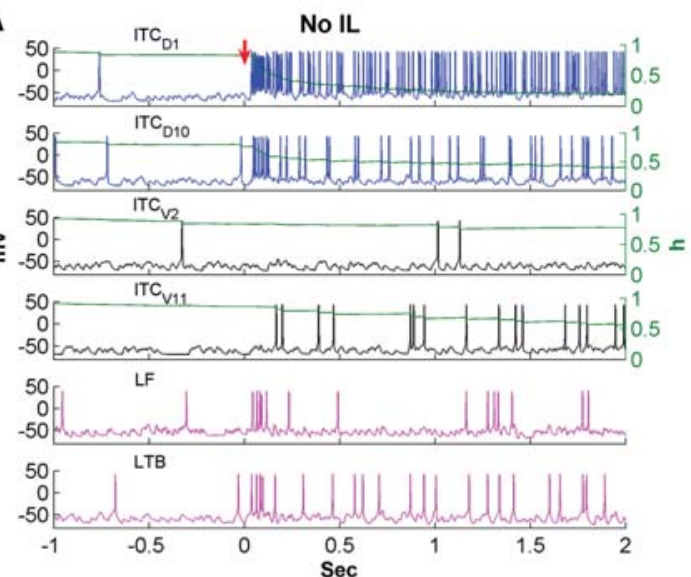

C

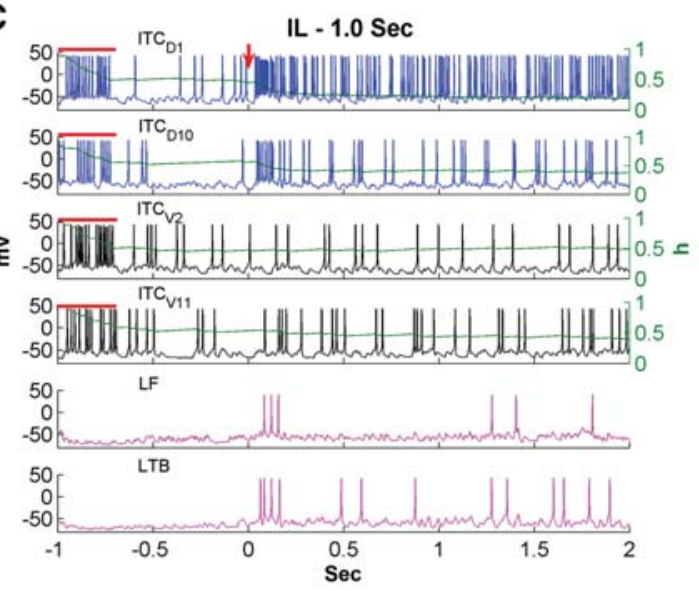

E

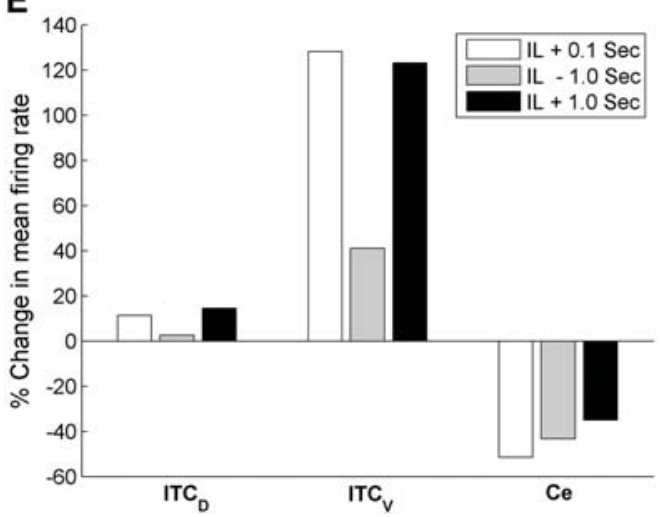

B

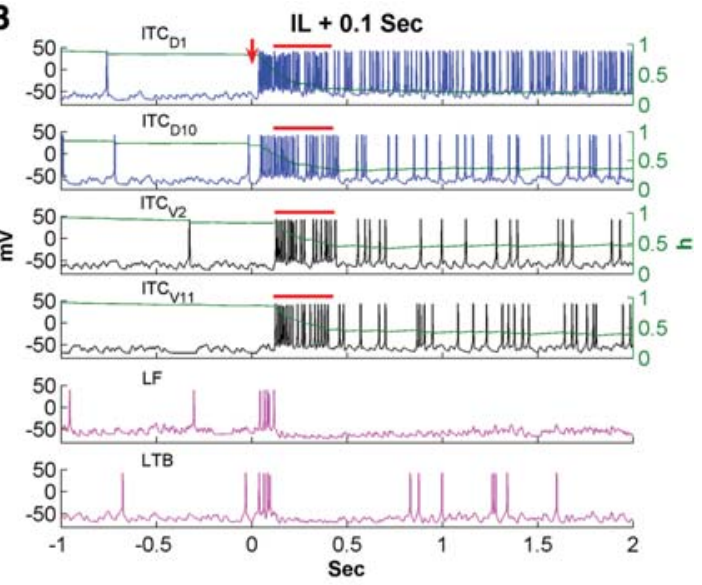

D

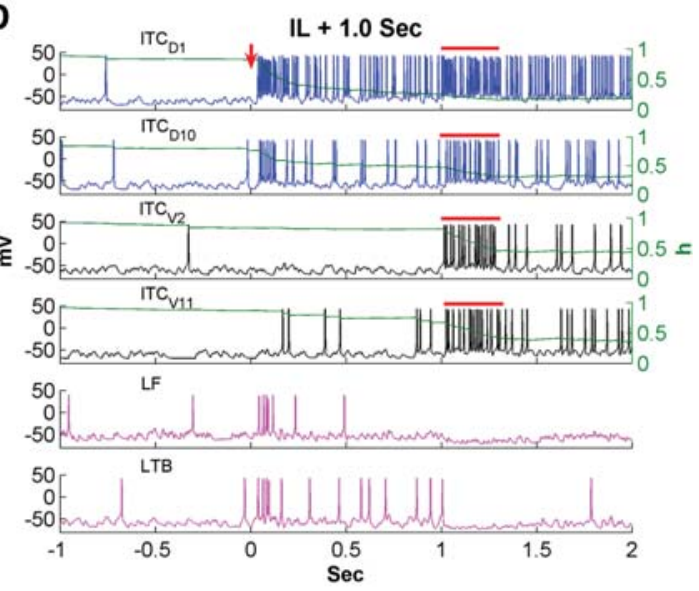

$\mathbf{F}$

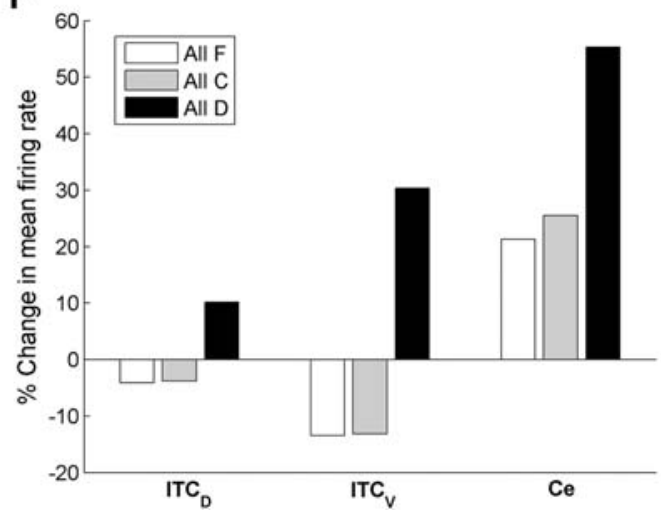

Figure 7. Impact of brief IL stimulation ( $300 \mathrm{msec}$ ) on network activity in the high fear state. Voltage responses of ITC $C_{D 1}$, ITC $C_{D 10}$, ITC $C_{V 2}$, ITC $C_{V 11}$, and two Ce neurons (one LF type and one LTB type) for the following four situations: ( $A$ ) High fear state without IL inputs; (B) IL inputs given at 0.1 sec after tone onset; (C) IL inputs given at $1 \mathrm{sec}$ before tone onset; $(D)$ IL inputs given $1 \mathrm{sec}$ after tone onset. The red arrows indicate CS onset and the red bars indicate the presence of IL inputs. (E) Percentage change in the mean firing frequency of ITC $C_{D}, I T C_{V}$, and Ce neurons for three different timings of IL stimulation relative to the fear case without IL inputs. $(F)$ Percentage change in the mean firing frequency of ITC $C_{D}$, ITC $C_{V}$, and Ce neurons for all facilitating, all depressing, and all constant-type synapse cases relative to the control case with heterogeneous synapses. IL stimulation is given at 0.1 sec after tone onset.

0.8 , close to that of the constant synapses). Hence, although not statistically significant, the mean Ce firing rates (over the 2-sec CS presentation) increased as the $\mathrm{ITC}_{\mathrm{V}}$ firing rates diminished under all facilitating or constant-type situations (all facilitating: $21.3 \%, t$-test $P>0.1$; all constant: $25.5 \%$, $t$-test $P>0.1$ ) (Fig. 7F). When all ITC synapses were of the depressing type, the CS-evoked firing rates of both $\mathrm{ITC}_{\mathrm{D}}$ and $\mathrm{ITC}_{\mathrm{V}}$ increased as inter-ITC inhibitory efficiency decreased $\left(\right.$ ITC $_{D}: 10.2 \%, t$-test
$P>0.1$; ITC $_{\mathrm{V}}: 30.3 \%$, $t$-test $P>0.1$ ). However, for this case, the efficiency of the ITC-Ce inhibition was much lower compared with the control case (see Supplemental Fig. S4, the release probability of depressing synapses at high rates was much lower than those of facilitating and constant synapses). This decrease in inhibition efficiency at the ITC-Ce synapses was found to overwhelm the opposing effect of increased $\mathrm{ITC}_{V}$ firing rate, and so the CS-evoked Ce firing rate was significantly higher than that 
in the control case $(55.3 \%$, from $4.7 \pm 0.7 \mathrm{~Hz}$ to $7.3 \pm 0.6 \mathrm{~Hz}$, $t$-test $P<0.05$ ) (Fig. 7F). Thus, these modeling experiments suggest that it is advantageous to have facilitating or constant type synapses for the ITC-Ce connection in order to inhibit Ce neurons effectively. Taken together, the results of our simulations indicate that variations in the short-term dynamics of ITC synapses enhance the effectiveness of IL inputs in reducing the expression of conditioned fear as expressed in the firing rate of Ce neurons.

\section{Discussion}

The IL cortex is believed to play a critical role in extinction by inhibiting fear output Ce neurons via the activation of ITC cells (Pare et al. 2004; Quirk and Mueller 2008). However, previous physiological studies have revealed that ITC cells inhibit each other (Royer et al. 2000a; Geracitano et al. 2007) raising the following question: Can IL inputs overcome the inter-ITC inhibition to regulate the CS-evoked activity of Ce neurons? Also, it is not clear how a brief IL stimulation (300 msec) can reduce fear expression effectively if given $100 \mathrm{msec}$ after tone onset, not earlier or later (Milad and Quirk 2002; Milad et al. 2004). Because it is currently difficult to test this experimentally, we investigated this problem using a biophysical network model. Our findings indicate that over a wide range of stimulation strengths, brief IL activation can overwhelm inter-ITC inhibition and reduce the activity of fear output Ce neurons. Importantly, both intrinsic properties (i.e., bistability) and variations in the short-term synaptic dynamics of ITC neurons contributed to the effectiveness of IL stimulation. In addition, we observed that ITC neurons could transform the transient CS-related signals arising in the BLA into a persistent pattern of activity. Below, we consider the significance of these observations in light of previous work about the physiology of ITC neurons.

\section{IL control of ITC cells and the regulation of conditioned fear expression}

Mounting evidence implicates ITC neurons in the regulation of conditioned fear expression. For instance, ITC lesions (Likhtik et al. 2008) as well as pharmacological inhibition of BLA inputs to ITC cells (Jungling et al. 2008) interfere with the extinction of conditioned fear responses. The inhibition of conditioned fear responses by ITC cells during extinction is thought to depend on their activation by glutamatergic inputs from the infralimbic cortex (Pare et al. 2004; Quirk and Mueller 2008). Several observations support this view. First, IL lesions interfere with the consolidation of extinction (Quirk et al. 2000). Second, IL sends a massive projection to ITC cells (McDonald et al. 1996; Freedman et al. 2000). Third, disinhibition of IL with local picrotoxin infusions leads to increased c-Fos expression in ITC cells (Berretta et al. 2005). Fourth, extinction testing is associated with marked increases in the number of c-Fos-positive IL and ITC cells (Knapska and Maren 2009). Last, electrical stimulation of IL produces a reduction of conditioned fear (Milad and Quirk 2002; Vidal-Gonzalez et al. 2006) and an abolition of BLA-evoked responses in Ce neurons (Quirk et al. 2003). In principle, ITC cells could produce the latter two effects by generating feedforward inhibition in Ce when activated by IL inputs (Pare and Smith 1993a,b; Royer et al. 1999).

However, other observations cast doubt on the validity of this interpretation. Indeed, ITC cells occur as densely packed clusters and there are connections between ITC cells located in the same (Geracitano et al. 2007) as well as different clusters (Royer et al. 2000a). The latter connections are directionally polarized, in the dorsoventral direction (Royer et al. 2000a). A further complication comes from the fact that inter-ITC connections show short-term plasticity (Geracitano et al. 2007). In a recent in vitro study, when presynaptic ITC cells were repeatedly activated with current injection in a range of frequencies, in an approximately equal proportion of cell pairs, transmitter release probability decreased, increased, or remained constant (Geracitano et al. 2007). As a result, it is not immediately clear whether IL inputs can overcome the inter-ITC inhibition and how the short-term plasticity of inter-ITC synapses might alter the impact of IL activity over time.

To examine these issues, we first developed a compartmental model of a single ITC cell that could reproduce their unusual electroresponsive properties, as observed experimentally (Royer et al. $2000 \mathrm{~b})$. These included their very high input resistance, repetitive firing behavior, and ability to transform transient suprathreshold depolarizations into prolonged periods of increased intrinsic excitability via the inactivation of a potassium current with slow deinactivation kinetics $\left(I_{\mathrm{SD}}\right)$. Next, we generated a larger ITC network that implemented the short-term synaptic plasticity of inter-ITC connections described above. The network behavior was then tested during patterns of BLA activation designed to simulate the rapidly adapting profile of activity evoked by CS presentations, as observed experimentally (Quirk et al. 1995; Pare and Collins 2000).

\section{Persistent modulation of Ce output by ITC neurons}

A first interesting observation to emerge from these tests was that despite the presence of inhibitory connections between ITC cells, transient excitatory inputs from BLA or IL were transformed by ITC cells into a sustained state of increased activity via the inactivation of $I_{\mathrm{SD}}$. Although the magnitude of this persistent activity was affected by the strength of inter-ITC inhibitory connections, it remained robust for higher inhibitory synaptic weights (2.5-fold change). Therefore, these results suggest that ITC cells express a form of short-term memory, inscribed in their intrinsic properties, allowing for persistent alterations in fear responsiveness following transient sensory signals. Burgos-Robles et al. (2009) recently demonstrated that prelimbic (PL) neurons transform transient amygdala inputs into a sustained output that drives conditioned fear responses and gates the expression of extinction. Therefore, it is possible that both PL and ITC activity contribute to sustaining the expression of conditioned fear. While PL seems to sustain fear by increasing the excitatory drive onto Ce via BA, the present study suggests that ITC $_{D}$ neurons could contribute to this sustenance by increasing their inhibition on $\mathrm{ITC}_{\mathrm{V}}$ neurons, resulting in disinhibition of Ce. As shown in Figure 8A, during the high fear state, strongly adaptive LA inputs were transformed into a sustained output by ITC $_{D}$ neurons, leading to persistent inhibition on ITC $_{V}$ cells and allowing for sustained Ce firing. Also, ITC neurons can support the expression of extinction via persistent activity in $\mathrm{ITC}_{\mathrm{V}}$ cells. In the extinction state (Fig. 8B), the LA responses diminished and the LA-ITC $\mathrm{D}_{\mathrm{D}}$ connection depotentiated, while the BA-ITC connection potentiated (Amano et al. 2010). Strongly adaptive BA inputs were then transformed into sustained firing in $\mathrm{ITC}_{\mathrm{V}}$ cells, resulting in lowered Ce responses.

\section{Can other mechanisms lead to sustained activity in the ITC network?}

Although diverse mechanisms underlying similar transitions from transient-to-sustained activity have been proposed in various brain areas (e.g., Wang 1999b; Egorov et al. 2002; Miller et al. 2003; Winograd et al. 2008), we believe that the slowly deinactivating current is the ionic basis for sustained ITC network activity due to the following reasons: (1) The ADPs displayed in ITC cells were not dependent on intracellular $\mathrm{Ca}^{2+} \mathrm{or} \mathrm{Na}^{+}$concentration (Royer et al. 2000b), suggesting that ADPs were not 

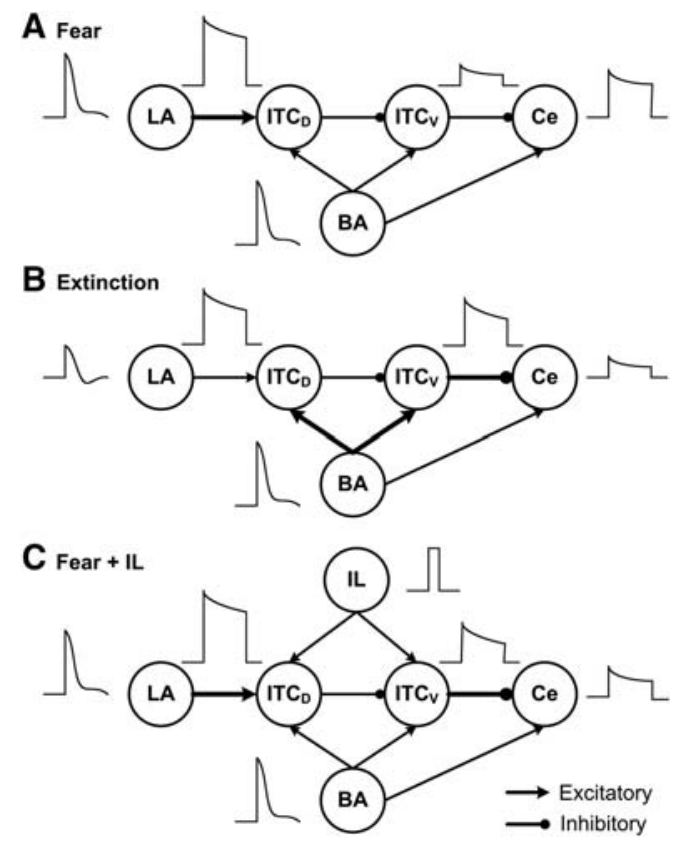

Figure 8. Schematic illustrating the patterns of neuronal activity in the amygdala under different network situations. In the high fear state $(A)$, the LA-ITC $C_{D}$ connection strength is potentiated. Strongly adaptive LA inputs are transformed into much sustained output by ITC $C_{D}$ neurons, leading to persistent inhibition on ITC $V$ cells allowing for sustained Ce firing. In the extinction state $(B)$, the LA inputs diminish and the LA-ITC $C_{D}$ synapses depotentiate, while the BA-ITC synapses potentiate. Similarly, strongly adaptive BA inputs are transformed by ITC $V$ neurons into sustained firing, leading to persistent inhibition of Ce output. When IL stimulation is given in the fear state $(C)$, brief IL inputs increase the excitability of both ITC $C_{D}$ and ITC $v$ neurons, with a larger impact on ITC $V$ cells, which significantly reduces the $\mathrm{Ce}$ firing. Note that the transmission efficiency (release probability) of the ITC $\mathrm{V}_{\mathrm{V}}$-Ce synapses is increased during extinction or with IL stimulation, enhancing inhibition on Ce output neurons.

mediated by a $\mathrm{Ca}^{2+}$-activated nonspecific cationic current $\left(I_{\mathrm{CAN}}\right)$. (2) A network-based mechanism seems unlikely here because the ADPs were not dependent on GABA release (Royer et al. 2000b). Indeed, the inhibitory interconnections between ITC cells serve to destabilize the persistent activity (Fig. 5). (3) Although ITC neurons express the HCN current $\left(I_{\mathrm{H}}\right)$, ITC cells rarely display rebound spikes following hyperpolarizing inputs (unpublished observation from the Pare lab). Indeed, to obtain sustained rebound spikes in the ITC cell model, the HCN channel density had to increase from 0.02 to $0.3 \mathrm{mS} / \mathrm{cm}^{2}$ and a large hyperpolarization was needed ( $-200 \mathrm{pA}$ ) (Supplemental Fig. S9). In light of earlier experimental observations, such a high HCN density is unlikely in ITC neurons. Similarly, the inhibitory connections between ITC cells are unlikely to lead to such large hyperpolarizations. Thus, we concluded that sustained ITC network activity is not due to the $I_{\mathrm{H}}$ current.

\section{IL stimulation reduces Ce responses to CS in a temporally specific manner}

Finally, we examined the impact of a brief IL stimulation (300 $\mathrm{msec}$ ) on the responsiveness of ITC cells to strongly adaptive CS-related BLA inputs, in the high fear state. IL inputs in a wide range of strengths caused a marked increase in the firing rate of ITC cells, strongly inhibiting the Ce output. Importantly, the impact of IL inputs extended beyond the $300-\mathrm{msec}$ stimulation window because IL-evoked firing caused a persistent inactivation of $I_{\mathrm{SD}}$ in ITC neurons (Fig. 7B-D). Also, the model demonstrated that IL stimulation given shortly after tone onset was most effective in reducing Ce firing, in agreement with experimental findings (Milad et al. 2004). This might be due to the fact that this timing most effectively combines the direct impact of IL in inhibiting early Ce spikes and its indirect (after IL is turned off) impact in inhibiting Ce firing subsequently, via the inactivation of $I_{\mathrm{SD}}$. Furthermore, model experiments revealed that variations in the short-term synaptic dynamics within the ITC network facilitates the inhibitory control of Ce output by IL (see the following section), a prediction that could be tested in future experiments. It can also be predicted that ITC neurons contacted by depressing synapses are more easily recruited by IL inputs than those contacted by facilitating or constant-type synapses.

\section{Implications of variations in the short-term dynamics of ITC synapses}

As mentioned above, three different types of short-term synaptic plasticity have been observed in inter-ITC connections (Geracitano et al. 2007), but the role of such synaptic heterogeneity is not clear. Our modeling experiments suggest that this synaptic heterogeneity can enhance the inhibitory control of Ce by IL inputs. First, to effectively inhibit Ce output, the $\mathrm{ITC}_{V}-\mathrm{Ce}$ connections have to be of the facilitating or constant types, as found experimentally (Geracitano et al. 2007). These two types of synapses maintain efficient levels of inhibition in Ce cells. In contrast, for the inter-ITC connections, pure facilitating or constant type synapses decrease the firing rates of both ITC $_{D}$ and $\mathrm{ITC}_{\mathrm{V}}$ neurons when IL inputs are active, resulting in elevated Ce responses (Fig. 7F). Hence, depressing synapses, in concert with $I_{\mathrm{SD}}$ inactivation, allow IL inputs to overcome the inter-ITC inhibition. Taken together, these considerations suggest that the heterogeneous short-term plasticity of the inter-ITC connections enables sufficiently high activity levels in $\mathrm{ITC}_{V}$ cells for an efficient control of fear-related Ce outputs when BA and IL neurons are active.

\section{Conclusions}

Overall, our results indicate that although the inhibitory connections between ITC cells tend to oppose excitatory influences onto them, both intrinsic and synaptic properties contribute to the inhibitory control of Ce by IL inputs. In particular, IL inputs do overcome the inhibition produced by inter-ITC connections, leading to an overall excitation of ITC cells and a persistent decrease in Ce fear outputs. These results support the notion that IL inputs are in strategic position to control extinction of conditioned fear via the activation of ITC neurons.

\section{Materials and Methods}

\section{ITC single cell model}

The ITC cell was modeled using the Hodgkin-Huxley formulation (Byrne and Roberts 2004). It had two compartments representing a soma (diameter of $8 \mu \mathrm{m}$; length of $8 \mu \mathrm{m}$ ) and a dendrite (diameter of $5 \mu \mathrm{m}$; length of $200 \mu \mathrm{m}$ ) (Millhouse 1986; Marowsky et al. 2005). The current balance equations were of the form given in Eqs. 1 and 2,

$$
\begin{aligned}
& C_{\mathrm{m}} \frac{\mathrm{d} V_{\mathrm{s}}}{\mathrm{d} t}=-g_{\mathrm{L}}\left(V_{\mathrm{s}}-E_{\mathrm{L}}\right)-g_{\mathrm{c}}\left(V_{\mathrm{s}}-V_{\mathrm{d}}\right)-\sum I_{\mathrm{s}}^{\mathrm{int}}-\sum I_{\mathrm{s}}^{\mathrm{syn}}+I_{\mathrm{s}} \\
& C_{\mathrm{m}} \frac{\mathrm{d} V_{\mathrm{d}}}{\mathrm{d} t}=-g_{\mathrm{L}}\left(V_{\mathrm{d}}-E_{\mathrm{L}}\right)-g_{\mathrm{c}}\left(V_{\mathrm{d}}-V_{\mathrm{s}}\right)-\sum I_{\mathrm{d}}^{\mathrm{int}}-\sum I_{\mathrm{d}}^{s y n}+I_{\mathrm{d}}
\end{aligned}
$$

where $V_{\mathrm{s}}$ and $V_{\mathrm{d}}$ were the somatic and dendritic membrane potentials $(\mathrm{mV}), I_{\mathrm{s}}^{\text {int }}\left(I_{\mathrm{d}}^{\text {int }}\right)$, and $I_{\mathrm{s}}^{\text {syn }}\left(I_{\mathrm{d}}^{\text {syn }}\right)$ were the intrinsic currents and 
the synaptic currents in the somatic (dendritic) compartments, respectively, $I_{\mathrm{s}}$ was the electrode current applied to the soma (or dendrite, $\left.I_{\mathrm{d}}\right), C_{\mathrm{m}}$ was the membrane capacitance, and $g_{\mathrm{c}}$ was the coupling conductance between the soma and the dendrite. The values for the specific membrane resistance, membrane capacitance, and cytoplasmic (axial) resistivity were, respectively, $R_{\mathrm{m}}=30 \mathrm{~K} \Omega-\mathrm{cm}^{2}, C_{\mathrm{m}}=1.0 \mu \mathrm{F} / \mathrm{cm}^{2}$, and $R_{\mathrm{a}}=150 \Omega-\mathrm{cm}$. The leakage reversal potential $\left(E_{\mathrm{L}}\right)$ was set to $-93 \mathrm{mV}$ to match experimental measurements of their resting potential $\left(V_{\text {rest }},-85 \mathrm{mV}\right.$; Geracitano et al. 2007; Amano et al. 2010). The resulting input resistance $\left(R_{\mathrm{IN}}\right)$ was about $600 \mathrm{M} \Omega$ when measured from rest, consistent with experimental observations (Royer et al. 2000a; Marowsky et al. 2005; Amano et al. 2010). The ITC model contained several ionic currents including a leakage current $I_{\mathrm{L}}$ a spike-generating sodium current $I_{\mathrm{Na}}$, a potassium delayed rectifier $I_{\mathrm{DR}}$, a slow deinactivating current $I_{\mathrm{SD}}$, a voltage-gated persistent muscarinic current $I_{\mathrm{M}}$, a hyperpolarization-activated current $I_{\mathrm{H}}$, a high-voltage activated $\mathrm{Ca}^{2+}$ current $I_{\mathrm{CaL}}$, and a slow $\mathrm{Ca}^{2+}$. dependent afterhyperpolarization current $I_{\mathrm{SAHP}}$. The ionic current for channel $i, I_{i}$, was modeled as $I_{i}=g_{i} m^{p} h^{q}\left(V-E_{i}\right)$, where $g_{i}$ was its maximal conductance, $m$ its activation variable (with exponent $p$ ), $h$ its inactivation variable (with exponent $q$ ), and $E_{i}$ its reversal potential. The kinetic equation for the gating variable $x$ $(m$ or $h)$ had the form

$$
\frac{\mathrm{d} x}{\mathrm{~d} t}=\frac{x_{\infty}\left(V,\left[\mathrm{Ca}^{2+}\right]_{i}\right)-x}{\tau_{x}\left(V,\left[\mathrm{Ca}^{2+}\right]_{i}\right)}
$$

where $x_{\infty}$ was the voltage- or $\mathrm{Ca}^{2+}$-dependent steady state and $\tau_{x}$ was the voltage- or $\mathrm{Ca}^{2+}$ - dependent time constant. The maximal conductance densities for all ionic currents and the expressions of $x_{\infty}$ and $\tau_{x}$ for each gating variable are listed in Supplemental Tables S1 and S2, respectively. The other reversal potentials were: $E_{\mathrm{Na}}=45 \mathrm{mV}, E_{\mathrm{K}}=-90 \mathrm{mV}, E_{\mathrm{Ca}}=120 \mathrm{mV}$, and $E_{\mathrm{H}}=-43 \mathrm{mV}$ (Huguenard and McCormick 1992).

\section{Ce single-cell models}

According to experimental findings (Dumont et al. 2002; De Armentia and Sah 2004), three different types of Ce neurons were modeled: regular spiking (RS), late firing (LF), and lowthreshold bursting (LTB). The Ce cell models also contained two compartments: a soma (diameter of $15 \mu \mathrm{m}$; length of $15 \mu \mathrm{m}$ ) and a dendrite (diameter of $5 \mu \mathrm{m}$; length of $300 \mu \mathrm{m}$ ). The Ce models included a leakage current $I_{\mathrm{L}}$, a sodium current $I_{\mathrm{Na}}$, a delayed rectifier $I_{\mathrm{DR}}$, a muscarinic current $I_{\mathrm{M}}$, a hyperpolarization-activated current $I_{\mathrm{H}}$, a high-voltage-activated $\mathrm{Ca}^{2+}$ current $I_{\mathrm{CaL}}$, and a slow $\mathrm{Ca}^{2+}$-dependent afterhyperpolarization current $I_{\text {SAHP }}$. The LF cell contained an additional inactivating transient $\mathrm{K}^{+}$current $I_{\mathrm{A}}$ known to delay the onset of the action potential (Storm 1986), while the LTB cell included an additional low-threshold inactivating calcium current $I_{\text {CaT }}$ (Dumont et al. 2002). The passive membrane properties were as follows: $R_{\mathrm{m}}=30 \mathrm{~K} \Omega-\mathrm{cm}^{2}$, $C_{\mathrm{m}}=1.0 \mu \mathrm{F} / \mathrm{cm}^{2}, R_{\mathrm{a}}=150 \Omega-\mathrm{cm}, E_{\mathrm{L}}=-60 \mathrm{mV}$ for LF cell, and $-70 \mathrm{mV}$ for RS and LTB cells.

\section{Current kinetics}

The kinetics of $I_{\mathrm{Na}}, I_{\mathrm{DR}}$, and $I_{\mathrm{CaL}}$ were adapted from a prefrontal cortex (PFC) model by Durstewitz et al. (2000), and those for $I_{\mathrm{A}}$, $I_{\mathrm{M}}$, and $I_{\mathrm{SAHP}}$ from Warman et al. (1994), who modeled CA1 hippocampal neurons. To adjust spiking threshold, the activation/inactivation functions of the $I_{\mathrm{Na}}$ current were shifted by $-3 \mathrm{mV}$ for ITC cells and $5 \mathrm{mV}$ for Ce neurons. A voltage shift of $20 \mathrm{mV}$ was also made in the inactivation function of the $I_{\mathrm{A}}$ current to achieve the desirable delay effect seen in LF Ce cells (Dumont et al. 2002; De Armentia and Sah 2004). The kinetics of the $I_{\mathrm{CaT}}$ current were taken from a granule cell model (Inoue and Strowbridge 2008) with the activation and inactivation functions shifted by $-15 \mathrm{mV}$ and $-10 \mathrm{mV}$, respectively, to replicate the firing patterns reported by Dumont et al. (2002). The mathematical description of $I_{\mathrm{H}}$ was based on a study of the current in rat BLA neurons
(Womble and Moises 1993). The detailed kinetics of the slow deinactivating conductance $I_{\mathrm{SD}}$ have not yet been characterized in ITC neurons, and we modeled this current as $I_{\mathrm{SD}}=g_{\mathrm{SD}} m^{4} h\left(V-E_{\mathrm{K}}\right)$ by modifying an "A" current (Huguenard and McCormick 1992) and adjusting the steady-state activation/inactivation with time constant functions to replicate the experimental observations of Royer et al. (2000b). The steady-state functions $m_{\infty}(V)$ and $h_{\infty}(V)$ are shown in Supplemental Figure S1A, and the inactivation time constant function $\tau_{h}(V)$ is shown in Supplemental Figure S1B. We note that the half-activation and half-inactivation voltages were about $-80 \mathrm{mV}$ and $-50 \mathrm{mV}$, respectively, and $I_{\mathrm{SD}}$ reached its maximum at around $-60 \mathrm{mV}\left(\mathrm{m}^{4} h\right.$ has the largest value), consistent with the observations of Royer et al. (2000b). The time constant of the inactivation variable was $100 \mathrm{msec}$ for $V>-30 \mathrm{mV}$ and it increased greatly for $V<-50 \mathrm{mV}$. Hence, $I_{\mathrm{SD}}$ activated fully in the subthreshold range $(V \approx-60 \mathrm{mV})$, inactivated slowly in response to suprathreshold depolarization $(V>-40 \mathrm{mV})$, and deinactivated very slowly $(V<-50 \mathrm{mV})$.

\section{Calcium dynamics}

Intracellular calcium was regulated by a simple first-order differential equation of the form (Warman et al. 1994):

$$
\frac{\mathrm{d}\left[\mathrm{Ca}^{2+}\right]_{i}}{\mathrm{~d} t}=-f \frac{I_{\mathrm{Ca}}}{z F V}+\frac{\left[\mathrm{Ca}^{2+}\right]_{\mathrm{rest}}-\left[\mathrm{Ca}^{2+}\right]_{i}}{\tau_{\mathrm{Ca}}}
$$

where $f$ is the fraction of the $\mathrm{Ca}^{2+}$ influx $(f=0.024)$ (Warman et al. 1994), $V=w A$ with $w$ the shell thickness $(1 \mu \mathrm{m}), A$ the cell surface area, $\mathrm{z}=2$ is the valence of the $\mathrm{Ca}^{2+}$ ion, $F$ is the Faraday constant, and $\tau_{\mathrm{Ca}}$ is the $\mathrm{Ca}^{2+}$ removal rate $\left(\tau_{\mathrm{Ca}}=80\right.$ msec) (Helmchen et al. 1996). The resting $\mathrm{Ca}^{2+}$ concentration $\left[\mathrm{Ca}^{2+}\right]_{\text {rest }}=0.05 \mu \mathrm{mol} / \mathrm{L}$, which was the same as the initial concentration (Durstewitz et al. 2000).

\section{Network structure and inputs}

The ITC-Ce network included 15 ITC $_{\mathrm{D}}$ and $15 \mathrm{ITC}_{\mathrm{V}}$ neurons, plus five Ce output cells (Fig. 1B). Among the five Ce neurons, three were LTB type, since these cells account for the majority of CeM (central medial nucleus) cells in the rat (Dumont et al. 2002), which the model was based on. The remaining two Ce neurons had one RS type and one LF type. Based on experimental findings (Geracitano et al. 2007), the synaptic connections between the ITC neurons were split equally into facilitating, depressing, and constant types (each neuron formed only one type of synapse with all its targets, as seen experimentally) (Geracitano et al. 2007). Each ITC neuron inhibited three other randomly selected neurons within the same cluster. This connectivity ratio $(20 \%)$ is higher than reported in Geracitano et al. (2007), and was needed to compensate for the fewer number of cells in our reduced network (Bazhenov et al. 2001). Also, based on earlier experimental reports (Royer et al. 1999, 2000a), each ITC $_{D}$ neuron inhibited three randomly selected ITC $_{V}$ neurons (the inhibitory connectivity among $\mathrm{ITC}_{\mathrm{D}}$ and $\mathrm{ITC}_{\mathrm{V}}$ cell clusters is shown in Supplemental Table S3).

The network received inputs from LA (lateral amygdala), BA (basal amygdala), and IL (Fig. 1B), which were modeled as realistic spike inputs rather than real neurons. LA inputs projected to ITC $C_{D}$, while IL inputs projected equally to $\mathrm{ITC}_{\mathrm{D}}$ and $\mathrm{ITC}_{\mathrm{V}}$ (McDonald et al. 1996). BA inputs also projected to both ITC $_{\mathrm{D}}$ and ITC $_{\mathrm{V}}$ clusters, but with a lower density to ITC $_{D}$ neurons (Royer et al. 1999, 2000a; Pape and Pare 2010). Based on the findings of Herry et al. (2008), the BA inputs were divided into fear, extinction, and extinction-resistant (ER) groups (Fig. 1B). Since the exact connectivity of each type of BA neurons with ITC and Ce neurons is currently unknown, we considered two possible network architectures. In the first architecture, all three types of BA inputs projected to ITC, while only extinction inputs projected to ITC in the second architecture. In both architectures, the extinction inputs did not project to Ce because the activation profile of 
extinction cells was opposite to the expression of fear (Herry et al. 2008). Instead, both fear and ER inputs projected to Ce.

We modeled $20 \mathrm{LA}, 20 \mathrm{BA}$, and $20 \mathrm{IL}$ inputs to the network. The relative ratio of each type of BA input was based on experimental data (Herry et al. 2008), which resulted in five fear, five extinction, and 10 ER inputs. Each LA input projected to three randomly selected $\mathrm{ITC}_{\mathrm{D}}$ neurons, and each $\mathrm{BA}$ input projected to two ITC $_{D}$ and 3 ITC $_{V}$ neurons, both again chosen randomly. The projection from IL to ITC appeared to be denser than that from BLA (McDonald et al. 1996). So each IL input projected to five ITC $\mathrm{D}_{\mathrm{D}}$ and five ITC $\mathrm{V}_{V}$ neurons selected at random. The Ce neurons received excitation from all BA fear and ER inputs, as well as inhibition from $\mathrm{ITC}_{\mathrm{V}}$ neurons of facilitating and constant type synapses (Pare and Smith 1993b; Royer et al. 1999; Pare et al. 2004; Geracitano et al. 2007). According to experimental observations (Geracitano et al. 2007), ITC $\mathrm{V}_{\mathrm{V}}$ cells forming depressing-type synapses did not project to Ce. The LA and BA inputs were modeled with different degrees of spike frequency adaptation based on previous experimental data (Quirk et al. 1995, 1997; Faber et al. 2001; Herry et al. 2008) and to account for the projection from LA to BA (Fig. 1B; Pitkanen 2000), the firing rate of BA fear inputs was assumed to be dependent on LA inputs due to similar firing patterns across training (Quirk et al. 1995; Herry et al. 2008; see Supplemental Materials and Methods for details). The IL inputs were modeled as Poisson-distributed spike trains with a duration of $300 \mathrm{msec}$ and a mean frequency of $20 \mathrm{~Hz}$ (Milad and Quirk 2002). In addition, Poisson-distributed random background inputs were delivered to all ITC and Ce neurons to achieve experimentally observed spontaneous firing rates.

\section{Synaptic currents}

In the model, excitatory synaptic transmission was mediated by glutamate acting at AMPA/NMDA receptors, while the inhibitory synapses were mediated by GABA acting at $\mathrm{GABA}_{\mathrm{A}}$ receptors (Sah et al. 2003). The AMPA/NMDA and $\mathrm{GABA}_{\mathrm{A}}$ synaptic currents were modeled by dual exponential functions as follows (Li et al. 2009):

$$
\begin{array}{r}
I_{\mathrm{AMPA}}=w \bar{A} g_{\mathrm{AMPA}, \max } \frac{\tau_{1} \tau_{2}}{\tau_{2}-\tau_{1}}\left[\exp \left(-t / \tau_{2}\right)-\exp \left(-t / \tau_{1}\right)\right] \\
\left.\left(V-E_{\mathrm{AMPA}}\right)\right) \frac{\tau_{1} \tau_{2}}{\tau_{2}-\tau_{1}}\left[\exp \left(-t / \tau_{2}\right)-\exp \left(-t / \tau_{1}\right)\right] \\
I_{\mathrm{NMDA}}=w \bar{A} g_{\mathrm{NMDA}, \max } S(V) \\
\left(V-E_{\mathrm{NMDA}}\right) \\
I_{\mathrm{GABAA}}=w \bar{A} g_{\mathrm{GABAA}, \max } \frac{\tau_{1} \tau_{2}}{\tau_{2}-\tau_{1}}\left[\exp \left(-t / \tau_{2}\right)-\exp \left(-t / \tau_{1}\right)\right] \\
\left(V-E_{\mathrm{GABAA}}\right)
\end{array}
$$

where $w$ was the synaptic weight given in Table $1, \bar{A}$ was a normalization constant chosen so that $g_{\mathrm{AMPA}}$ max, $g_{\mathrm{NMDA}}$, max , and $g_{\text {GABAA, }}$ max assumed maximum values of the conductances (when $w=1$ ); $\tau_{1}$ and $\tau_{2}$ were the rise and decay time constants, respectively. For AMPA receptor channels, $\tau_{1}=0.5 \mathrm{msec}$ and $\tau_{2}=7 \mathrm{msec}$ for ITC cells and $\tau_{1}=1.8 \mathrm{msec}$ and $\tau_{2}=4.4 \mathrm{msec}$ for Ce neurons (De Armentia and Sah 2003). For NMDA receptor channels, $\tau_{1}=5 \mathrm{msec}$ and $\tau_{2}=125 \mathrm{msec}$ for ITC cells and $\tau_{1}=5$ msec and $\tau_{2}=162 \mathrm{msec}$ for Ce neurons (De Armentia and Sah 2003). The voltage-dependent variable $s(V)$, which implements the $\mathrm{Mg}^{2+}$ block of NMDA receptors, was defined as: $s(V)=[1+0.33 \exp (-0.06 \mathrm{~V})]^{-1}$ (Zador et al. 1990). For the $\mathrm{GABA}_{\mathrm{A}}$ synaptic current, $\tau_{1}=0.8 \mathrm{msec}, \tau_{2}=13 \mathrm{msec}$ for ITC cells (Geracitano et al. 2007), and $\tau_{1}=0.8 \mathrm{msec}, \tau_{2}=40 \mathrm{msec}$ for Ce neurons (Esmaeili et al. 2009). The maximal conductances were chosen as: $g_{\mathrm{AMPA}}, \max =1 \mathrm{nS}, g_{\mathrm{NMDA}}$ max $=0.5 \mathrm{nS}$ (Li et al. 2009), and $g_{\text {GABAA, } \max }=0.6 \mathrm{nS}$ (Geracitano et al. 2007). Synaptic reversal potentials were set as $E_{\mathrm{AMPA}}=E_{\mathrm{NMDA}}=0 \mathrm{mV}, E_{\mathrm{GABAA}}=-\tau 75 \mathrm{mV}$ (Li et al. 2009). The $\mathrm{GABA}_{\mathrm{A}}$ conductance profile of ITC neurons is shown in Supplemental Figure S3.The synaptic delay was chosen randomly between a minimal and a maximal values with a uniform probability, based on experimental data from the Pare lab (Supplemental Table S4).

\section{Presynaptic release probability}

As observed experimentally (Geracitano et al. 2007), short-term synaptic plasticity in ITC-ITC connections is heterogeneous (facilitating, depressing, and constant) and depends on presynaptic firing rates. As presynaptic stimulation frequency increases, the release probability of facilitating synapses increases, while that of depressing synapses decreases, and that of constant synapses remains unchanged. Such plasticity is also assumed to exist in the $\mathrm{ITC}_{\mathrm{V}}-\mathrm{Ce}$ connections. In the model, presynaptic release probability was updated according to the following learning rule:

$$
\frac{\mathrm{d} p}{\mathrm{~d} t}=\frac{\Phi(F)-p}{\tau}
$$

where the time constant $\tau$ was selected to be $100 \mathrm{msec}$ (Wang 1999a; a larger time constant of 300 msec yielded similar results), $\Phi$ was a function of the presynaptic firing frequency $F$, determined by nonlinear regression modeling of the experimental data (Geracitano et al. 2007; Supplemental Fig. S4). When a presynaptic spike occurred, the presynaptic frequency was updated as the running average of the current and three previous instantaneous frequencies: $F_{n}=a_{1} f_{n}+a_{2} f_{n-1}+a_{3} f_{n-2}+a_{4} f_{n-3}\left(a_{1}=0.4\right.$, $\left.a_{3}=0.2, a_{3}=0.2, a_{4}=0.1\right)$, where $f_{n}=1 / \Delta T_{n}$ and $\Delta T_{\mathrm{n}}$ was the interval between the previous and current spikes. Between spikes, $F$ decayed back towards zero with a time constant of 5 sec (a relatively large time constant was chosen to avoid rapid frequency decay between spikes). When a presynaptic spike occurred, a uniform pseudo-random number $P_{\mathrm{r}}$ between 0 and 1 (using the rand function in $\mathrm{C}++$ ) was generated. If $P_{\mathrm{r}}$ was less than the current release probability $p$ then neurotransmitter release was successful, otherwise it was not. The initial release probability was 0.3 and 0.8 for the facilitating and depressing synapses, respectively, and the release probability of constant synapses was fixed at 0.75 (Geracitano et al. 2007).

\section{Synaptic strengths in three network states}

We simulated network responses to a 2-sec auditory tone input (CS) during three different network states: habituation, following fear conditioning, and after extinction training. Learning of fear and extinction is accompanied by changes in synaptic strengths in the neural circuitry of the amygdala (Pape and Pare 2010). ITC neurons exhibit NMDA-dependent bidirectional synaptic plasticity (Royer and Pare 2002) and in a recent experimental study, the BA inputs to ITC cells are found to be potentiated in extinction training (approximately threefold; Fig. 4 in Amano et al. 2010). Given the fact that the firing rate of LA neurons is significantly increased after conditioning (Quirk et al. 1995), it is reasonable to assume that the LA-ITC ${ }_{\mathrm{D}}$ connection is potentiated by conditioning. Hence, we used a threefold synaptic weight (compared with the habituation state) for the LA-ITC $C_{D}$ synapses in the fear state and a threefold synaptic weight for the BA-ITC synapses in the extinction state (Table 1). For the LA-ITC ${ }_{D}$ connection, the potentiated synapses were assumed to be partially depotentiated in the extinction state (Table 1 ) based on results from a previous LA network model (Li et al. 2009). Note that the potentiation was only imposed on the AMPA components of the synapses (Amano et al. 2010). The BA-Ce, ITC-ITC, and ITC-Ce synaptic weights were assumed to be fixed, but the presynaptic release probability of the ITC-ITC and ITC-Ce synapses was modifiable (Geracitano et al. 2007).

\section{Implementation of model}

Model runs were performed on a personal computer using the software package GENESIS (Bower and Beeman 2003) with the Crank-Nicholson integration method, and a time step of $20 \mu \mathrm{sec}$. Shorter time steps did not change the results in any significant way. The (background) input onset was $1 \mathrm{sec}$ after the start of the simulation to allow the model cells to stabilize. A simulation of $5 \mathrm{sec}$ of network activity took $15 \mathrm{~min}$ of CPU time. 


\section{Limitations}

Admittedly, our model has some limitations: (1) Given the restricted amount of detailed electrophysiological data about ITC cells, we had to use data on ionic conductance from other brain areas such as hippocampus and cortex. (2) In the absence of more specific information, IL was assumed to project equally to dorsal and ventral clusters. Also, we assumed the same connectivity ratio within the ITC clusters and between the clusters. (3) The network size was designed to be relatively small in order to avoid computational overload. It remains to be determined whether the qualitative conclusions and predictions of the model will hold for a larger network. (4) When dealing with the effectiveness of IL stimulation, the role of IL inputs in facilitating plasticity at BA-ITC synapses (Amano et al. 2010) was not taken into account. (5) Although it was previously reported that the lateral sector of the central nucleus $(\mathrm{CeL})$ projects to CeM (Petrovich and Swanson 1997; Jolkkonen and Pitkanen 1998), CeL was not included in our model. This omission resulted from the paucity of data available to constrain the model. However, as we were completing the present investigation, two studies provided evidence that CeL activity might play an important role in the genesis of conditioned fear responses. In particular, it was shown that pretraining inhibition of CeL with muscimol (Ciocchi et al. 2010) or silencing of a subset of CeL cells expressing PKC- $\delta$ (Haubensak et al. 2010) interfered with the acquisition of conditioned fear. Moreover, after fear conditioning, CS presentations inhibited PKC- $\delta$ expressing CeL cells (hereafter termed $\mathrm{CeL}^{-}$neurons) (Ciocchi et al. 2010; Haubensak et al. 2010), whereas PKC- $\delta$ negative CeL neurons were excited by the CS (hereafter termed $\mathrm{CeL}^{+}$cells). The existence of inhibitory connections between $\mathrm{CeL}^{+}$and $\mathrm{CeL}^{-}$neurons implied that when the CS is presented, $\mathrm{CeL}^{+}$cells inhibit $\mathrm{CeL}^{-}$neurons resulting in the disinhibition of CeM fear output neurons (Ciocchi et al. 2010; Haubensak et al. 2010). Future modeling studies should consider how CeL activity interacts with ITC inputs to regulate the excitability of CeM neurons and fear expression.

\section{Acknowledgments}

This research was supported in part by NIMH grants MH087755 to S.S.N. and MH083710 to D.P. We thank Dr. Gregory Quirk for helpful discussions and comments on an earlier draft.

\section{References}

Amano T, Unal CT, Pare D. 2010. Synaptic correlates of fear extinction in the amygdala. Nat Neurosci 13: 489-494.

Bazhenov M, Stopfer M, Rabinovich M, Huerta R, Abarbanel HDI, Sejnowski TJ, Laurent G. 2001. Model of transient oscillatory synchronization in the locust antennal lobe. Neuron 30: 553-567.

Berretta S, Pantazopoulos H, Caldera M, Pantazopoulos P, Pare D. 2005. Infralimbic cortex activation increases c-Fos expression in intercalated neurons of the amygdala. Neuroscience 132: 943-953.

Bower JM, Beeman D. 2003. The book of GENESIS: Exploring realistic neural models with the GEneral NEural SImulation System. Internet edition (http://www.genesis-sim.org/GENESIS).

Burgos-Robles A, Vidal-Gonzalez I, Quirk GJ. 2009. Sustained conditioned responses in prelimbic prefrontal neurons are correlated with fear expression and extinction failure. J Neurosci 29: 8474-8482.

Byrne JH, Roberts JL. 2004. From molecules to networks - An introduction to cellular and molecular neuroscience. Elsevier Academic Press, London, UK.

Ciocchi S, Herry C, Grenier F, Wolff SBE, Letzkus JJ, Vlachos I, Ehrlich I, Sprengel R, Deisseroth K, Stadler MB, et al. 2010. Encoding of conditioned fear in central amygdala inhibitory circuits. Nature 468: $277-282$.

De Armentia ML, Sah P. 2003. Development and subunit composition of synaptic NMDA receptors in the amygdala: NR2B synapses in the adult central amygdala. J Neurosci 23: 6876-6883.

De Armentia ML, Sah P. 2004. Firing properties and connectivity of neurons in the rat lateral central nucleus of the amygdala. J Neurophysiol 92: $1285-1294$

Dumont É, Martina M, Samson R, Drolet G, Pare D. 2002. Physiological properties of central amygdala neurons: Species differences. Eur I Neurosci 15: 545-552.
Durstewitz D, Seamans JK, Sejnowski TJ. 2000. Dopamine-mediated stabilization of delay-period activity in a network model of prefrontal cortex. J Neurophysiol 83: 1733-1750.

Duvarci S, Popa D, Pare D. 2011. Central amygdala activity during fear conditioning. J Neurosci 31: 289-294.

Egorov AV, Hamam BN, Fransén E, Hasselmo ME, Alonso AA. 2002 Graded persistent activity in entorhinal cortex neurons. Nature 420: $173-178$.

Esmaeili A, Lynch JW, Sah P. 2009. GABA $A_{A}$ receptors containing gamma1 subunits contribute to inhibitory transmission in the central amygdala. J Neurophysiol 101: 341-349.

Faber ESL, Callister RJ, Sah P. 2001. Morphological and electrophysiological properties of principal neurons in the rat lateral amygdala in vitro. $J$ Neurophysiol 85: 714-723.

Freedman LJ, Insel TR, Smith Y. 2000. Subcortical projections of area 25 (subgenual cortex) of the macaque monkey. J Comp Neurol 42: $172-188$.

Geracitano R, Kaufmann WA, Szabo G, Ferraguti F, Capogna M. 2007. Synaptic heterogeneity between mouse paracapsular intercalated neurons of the amygdala. J Physiol 585: 117-134.

Haubensak W, Kunwar PS, Cai H, Ciocchi S, Wall NR, Ponnusamy R, Biag J, Dong HW, Deisseroth K, Callaway EM, et al. 2010. Genetic dissection of an amygdala microcircuit that gates conditioned fear. Nature 468: 270-276.

Helmchen F, Imoto K, Sakmann B. 1996. $\mathrm{Ca}^{2+}$ buffering and action potential-evoked $\mathrm{Ca}^{2+}$ signaling in dendrites of pyramidal neurons. Biophys J 70: $1069-1081$.

Herry C, Ciocchi S, Senn V, Demmou L, Müller C, Lüthi A. 2008. Switching on and off fear by distinct neuronal circuits. Nature 454: 600-606.

Huguenard JR, McCormick DA. 1992. Simulation of the currents involved in rhythmic oscillations in thalamic relay neurons. J Neurophysiol 68: $1373-1383$.

Inoue T, Strowbridge BW. 2008. Transient activity induces a long-lasting increase in the excitability of olfactory bulb interneurons. Neurophysiol 99: 187-199.

Jolkkonen E, Pitkanen A. 1998. Intrinsic connections of the rat amygdaloid complex: Projections originating in the central nucleus. J Comp Neurol 395: $53-72$.

Jungling K, Seidenbecher T, Sosulina L, Lesting J, Sangha S, Clark SD, Okamura N, Duangdao DM, Xu YL, Reinscheid RK, et al. 2008. Neuropeptide S-mediated control of fear expression and extinction: Role of intercalated GABAergic neurons in the amygdala. Neuron 59: 298-310.

Knapska E, Maren S. 2009. Reciprocal patterns of c-Fos expression in the medial prefrontal cortex and amygdala after extinction and renewal of conditioned fear. Learn Mem 16: 486-493.

Li G, Nair SS, Quirk GJ. 2009. A biologically realistic network model of acquisition and extinction of conditioned fear associations in lateral amygdala neurons. J Neurophysiol 101: 1629-1646.

Likhtik E, Popa D, Apergis-Schoute A, Fidacaro GA, Pare D. 2008. Amygdala intercalated neurons are required for expression of fear extinction. Nature 454: 642-645.

Marowsky A, Yanagawa Y, Obata K, Vogt KE. 2005. A specialized subclass of interneurons mediates dopaminergic facilitation of amygdala function. Neuron 48: 1025-1037.

McDonald AJ, Mascagni F, Guo L. 1996. Projections of the medial and lateral prefrontal cortices to the amygdala: A Phaseolus vulgaris leucoagglutinin study in the rat. Neuroscience 71: 55-75.

Milad MR, Quirk GJ. 2002. Neurons in medial prefrontal cortex signal memory for fear extinction. Nature 420: $70-74$.

Milad MR, Vidal-Gonzalez I, Quirk GJ. 2004. Electrical stimulation of medial prefrontal cortex reduces conditioned fear in a temporally specific manner. Behav Neurosci 118: 389-394.

Miller P, Brody CD, Romo R, Wang X-J. 2003. A recurrent network model of somatosensory parametric working memory in the prefrontal cortex. Cerebral Cortex 13: $1208-1218$.

Millhouse OE. 1986. The intercalated cells of the amygdala. J Comp Neurol 247: $246-271$

Pape HC, Pare D. 2010. Plastic synaptic networks of the Amygdala for the acquisition, expression, and extinction of conditioned fear. Physiol Rev 90: $419-463$

Pare D, Collins DR. 2000. Neuronal correlates of fear in the lateral amygdala: Multiple extracellular recording in conscious cats. J Neurosci 20: $2701-2710$.

Pare D, Smith Y. 1993a. Distribution of GABA immunoreactivity in the amygdaloid complex of the cat. Neuroscience 57: 1061-1076.

Pare D, Smith Y. 1993b. The intercalated cell masses project to the central and medial nuclei of the amygdala in cats. Neuroscience 57: $1077-1090$

Pare D, Quirk GJ, LeDoux JE. 2004. New vistas on amygdala networks in conditioned fear. J Neurophysiol 92: 1-9. 
Petrovich GD, Swanson LW. 1997. Projections from the lateral part of the central amygdalar nucleus to the postulated fear conditioning circuit. Brain Research 763: 247-254.

Pitkanen A. 2000. Connectivity of the rat amygdaloid complex. In The amygdala: A functional analysis, 2nd ed. ( ed. JP Aggleton), pp. 31-115. Oxford University Press, Oxford, UK.

Quirk GJ, Mueller D. 2008. Neural mechanisms of extinction learning and retrieval. Neuropsychopharmacol 33: 56-72.

Quirk GJ, Repa C, LeDoux JE. 1995. Fear conditioning enhances short-latency auditory responses of lateral amygdala neurons: Parallel recordings in the freely behaving rat. Neuron 15: 1029-1039.

Quirk GJ, Armony JL, LeDoux JE. 1997. Fear conditioning enhances different temporal components of tone-evoked spike trains in auditory cortex and lateral amygdala. Neuron 19: 613-624.

Quirk GJ, Russo GK, Barron JL, Lebron K. 2000. The role of ventromedial prefrontal cortex in the recovery of extinguished fear. J Neurosci 20: 6225-6231.

Quirk GJ, Likhtik E, Pelletier JG, Pare D. 2003. Stimulation of medial prefrontal cortex decreases the responsiveness of central amygdala output neurons. J Neurosci 23: 8800-8807.

Repa JC, Muller J, Apergis J, Desrochers TM, Zhou Y, LeDoux JE. 2001. Two different lateral amygdala cell populations contribute to the initiation and storage of memory. Nature Neurosci 4: 724-731.

Royer S, Pare D. 2002. Bidirectional synaptic plasticity in intercalated amygdala neurons and the extinction of conditioned fear responses. Neuroscience 115: 455-462.

Royer S, Martina M, Pare D. 1999. An inhibitory interface gates impulse traffic between the input and output stations of the amygdala. $J$ Neurosci 19: 10575-10583.

Royer S, Martina M, Pare D. 2000a. Polarized synaptic interactions between intercalated neurons of the amygdala. J Neurophysiol 83: 3509-3518.
Royer S, Martina M, Pare D. 2000b. Bistable behavior of inhibitory neurons controlling impulse traffic through the amygdala: Role of a slowly deinactivating $\mathrm{K}^{+}$current. J Neurosci 20: 9034-9039.

Sah P, Faber ESL, De Armentia ML, Power J. 2003. The amygdaloid complex: Anatomy and physiology. Physiol Rev 83: 803-834.

Storm JF. 1986. A-current and Ca-dependent transient outward current control the initial repetitive firing in hippocampal neurons. (Abstract). Biophys J 49: 369.

Vidal-Gonzalez I, Vidal-Gonzalez B, Rauch SL, Quirk GJ. 2006. Microstimulation reveals opposing influences of prelimbic and infralimbic cortex on the expression of conditioned fear. Learn Mem 13: $728-733$

Wang X-J. 1998. Calcium coding and adaptive temporal computation in cortical pyramidal neurons. I Neurophysiol 79: 1549-1566.

Wang X-J. 1999a. Fast burst firing and short-term synaptic plasticity: A model of neocortical chattering neurons. Neuroscience 89: 347-362.

Wang X-J. 1999b. Synaptic basis of cortical persistent activity: The importance of NMDA receptors to working memory. J Neurosci 19: 9587-9603.

Warman EN, Durand DM, Yuen GLF. 1994. Reconstruction of hippocampal CA1 pyramidal cell electrophysiology by computer simulation. J Neurophysiol 71: 2033-2045.

Winograd M, Destexhe A, Sanchez-Vives MV. 2008. Hyperpolarizationactivated graded persistent activity in the prefrontal cortex. PNAS 105: $7298-7303$.

Womble MD, Moises HC. 1993. Hyperpolarization-activated currents in neurons of the rat basolateral amygdala. J Neurophysiol 70: 2056-2065.

Zador A, Koch C, Brown TH. 1990. Biophysical model of a Hebbian synapse. Proc Natl Acad Soc 87: 6718-6722.

Received July 15, 2010; accepted in revised form February 2, 2011. 


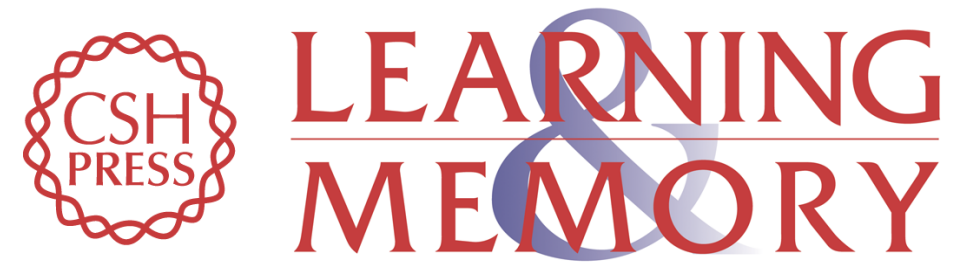

\title{
Impact of infralimbic inputs on intercalated amygdala neurons: A biophysical modeling study
}

\author{
Guoshi Li, Taiju Amano, Denis Pare, et al.
}

Learn. Mem. 2011, 18:

Access the most recent version at doi:10.1101//m.1938011

\section{Supplemental http://learnmem.cshlp.org/content/suppl/2011/03/24/18.4.226.DC1 Material}

References

This article cites 57 articles, 12 of which can be accessed free at: http://learnmem.cshlp.org/content/18/4/226.full.html\#ref-list-1

License

Email Alerting

Receive free email alerts when new articles cite this article - sign up in the box at the Service top right corner of the article or click here. 